\title{
A fuzzy multiple attribute decision making tool for HVAC\&R systems selection with considering the future probabilistic climate changes and electricity decarbonisation plans in the UK
}

Article

Accepted Version

Creative Commons: Attribution-Noncommercial-No Derivative Works 4.0

Shahrestani, M., Yao, R. and Cook, G. K. (2018) A fuzzy multiple attribute decision making tool for HVAC\&R systems selection with considering the future probabilistic climate changes and electricity decarbonisation plans in the UK. Energy and Buildings, 159. pp. 398-418. ISSN 0378-7788 doi: https://doi.org/10.1016/j.enbuild.2017.10.089 Available at https://centaur.reading.ac.uk/73923/

It is advisable to refer to the publisher's version if you intend to cite from the work. See Guidance on citing.

To link to this article DOI: http://dx.doi.org/10.1016/j.enbuild.2017.10.089

Publisher: Elsevier

All outputs in CentAUR are protected by Intellectual Property Rights law, including copyright law. Copyright and IPR is retained by the creators or other copyright holders. Terms and conditions for use of this material are defined in the End User Agreement. 


\section{www.reading.ac.uk/centaur}

\section{CentAUR}

Central Archive at the University of Reading

Reading's research outputs online 
Shahrestani, M., Yao, R. and Cook, G. K. (2018). A fuzzy multiple attribute decision making tool for HVAC\&R systems selection with considering the future probabilistic climate changes and electricity decarbonisation plans in the UK. Energy and Buildings, 159, 398-418. https://doi.org/10.1016/i.enbuild.2017.10.089

\section{A fuzzy multiple attribute decision making tool for HVAC\&R systems selection with considering the future probabilistic climate changes and electricity decarbonisation plans in the UK}

Mehdi Shahrestani ${ }^{\mathrm{a}, *}$, Runming Yao ${ }^{a}$, Geoffrey K Cook ${ }^{\mathrm{a}}$

a: School of the Built Environment, University of Reading, Whiteknights, PO Box 219,

Reading, Berkshire, UK

*Corresponding author: m.shahrestani@reading.ac.uk, Tel.: +44 (0) 1183787575

\section{Abstract:}

Buildings account for $40 \%$ of total energy consumption in the UK and more than $55 \%$ of this energy is used by heating, ventilation, air-conditioning and refrigeration (HVAC\&R) systems. This significant energy demand and the ascending trend in utilising HVAC\&R systems together with the global need to impose energy-efficiency measures underline the importance of selecting the most appropriate HVAC\&R system during the design process.

This paper reviewed and classified a broad range of principal multiple attribute decision making methods. Among them, the fuzzy multiple attribute decision making approach was adopted to develop a decision making tool for HVAC\&R systems selection. This was mainly due to the ability of this method to deal with the uncertainties and imprecisions of the linguistic terms involved in the decision making process. In order to make a decision on HVAC\&R systems selection, 58 alternative systems, including both primary and secondary parts, were examined. The scope of this study enabled the consideration of all 18 climate regions in the UK and included the effects of climate change. In addition, the Government's electricity decarbonisation plans were integrated within the developed decision making model for HVAC\&R systems selection in office buildings in the UK. Finally, the model was transferred into a computational tool with a user-friendly interface.

\section{Keywords:}

Multiple attribute decision making, Fuzzy Decision making, Climate change, Global warming, Building energy, HVAC\&R systems selection 


\section{Introduction}

Decision making is a process of choosing from two or more alternative courses or actions for the purpose of attaining a goal (Turban, 1988; Natee et al., 2016). Every individual makes numerous personal decisions of varying importance everyday. These daily decisions can be made based on the individual's intuitions because a few options and limited number of criteria associated with these decisions. However, this is not the case when a decision must be made in a more complex environment, which involves several options and interrelated criteria. In such a complex decision making environment, a formal and transparent decision making process should be able to provide (Baker et al., 2001; DCLG, 2009):

- Documented, transparent and explicit assumptions, criteria, and scores used to make decisions,

- Consistent and rational decisions that are repeatable, reviewable, revisable, and easy to understand

The U.S. Department of Energy (DoE) recommends formal decision makings in several cases including circumstances that decisions (Baker et al., 2001):

- Require many reviews at different management levels,

- Affect new or redirected funding,

- Require approval for new facilities or upgrades to existing facilities,

- Have alternatives that appear equally viable,

- Have impact mainly in the future.

All these circumstances are applicable for HVAC\&R systems selection, which has to be reviewed in different managerial levels (Langmaid, 2004; Phillips, 2008). In addition, different types of HVAC\&R systems require different levels of investment (Davis Langdon, 2016). Also, the process of selecting a specific type of HVAC\&R system needs to involve the design team and the facility manager in order to insure that the necessary space and access requirements during both the design and operation period are provided (Atkin and Brooks, 2009; Hawkins, 2009). Moreover, several combinations of primary and secondary HVAC\&R systems can be considered for an individual building, which might appear equally viable in one aspect, for 
example, indoor air quality but different in other aspects, for example, energy consumption (Maor et al., 2004; Avgelis and Papadopoulos, 2009). Finally, HVAC\&R systems have a significant environmental impacts due to their energy related $\mathrm{CO}_{2}$ emissions during operation. This in turn has an undeniable influence on global warming and climate change (DECC, 2012). All these confirms the need for a formal decision making tool for HVAC\&R systems selection. Review of the open literature has revealed that the main gap in this field is the lack of an integrated tool for HVAC\&R systems selection that is able to (Shahrestani, 2013, Shahrestani et al., 2017):

- Consider a broad range of alternative systems,

- Assist designers and decision makers not only researchers,

- Analyse the alternatives based on reliable sources of information,

- Consider the radical changes in the future; for example, climate change and global warming within the context of a decision making process,

- Rank the alternative HVAC\&R systems based on a robust and formal decision making process.

This study aims to address these needs by proposing a fuzzy decision making model and developing a computational tool to help designers and decision makers in the process of decision making for HVAC\&R systems selection.

\subsection{Multiple criteria decision making (MCDM)}

Real World decisions are often made with respect to multiple criteria to achieve simultaneous goals, of which some of them are mutually conflicting. For example in this study, for HVAC\&R systems selection, more than one criterion needs to be considered. Therefore, in such cases, multiple criteria decision making (MCDM) methods are more appropriate.

The application of MCDM is very broad; however, all the applications of the MCDM can be categorised into two groups (Hwang and Yoon, 1981):

- Multiple Attribute Decision Making (MADM)

- Multiple Objective Decision Making (MODM) 
The main difference between these two approaches is that multiple attribute decision making (MADM) is performed in a discrete decision space and focuses on how to select and rank different predetermined explicit alternatives (Zimmermann, 2001; Kahraman, 2008). Several MADM techniques are developed to deal with these subjective preferences which are described in the next section. Conversely, multiple objective decision making (MODM) concentrates on continuous decision spaces aimed to determine the optimal or aspired goals by considering several objective functions within a predefined constraints of a decision making problem (Zimmermann, 2001; Tzeng and Huang, 2011).

\subsection{Multiple attribute decision making (MADM) methods}

MADM is a well-known branch of decision making within the general class of operations research models (Kahraman, 2008). In the MADM approach, the selection is made from a limited number of decision alternatives, which are explicitly described by their attributes.

A variety of MADM methods is introduced in the literature. Hwang and Yoon (1981) categorised 17 MADM methods according to the type and salient features of the information that each method needs in order to make a decision. This categorisation was modified and a new taxonomy of MADM including 13 methods was provided by Yoon and Hwang (1995). In another study, Norris and Marshall (1995) classified MADM methods based on three parameters: 1 - level of information needed for decision making, 2 - the relative compensatory effects of the methods, and 3 - whether a method aims to screen and/or rank the alternatives or only to offer the best available choice. Most recently, Wang et al. (2009c) introduced a different categorisation of MADM methods using three broad groups; 1 - elementary methods, 2 - outranking methods, and 3 - unique synthesising criteria methods.

In this paper, the parameters used to categorise MADM methods in the aforementioned studies are aggregated and used as a basis for introducing a new and more detailed classification of the MADM methods. The proposed new classification of MADM methods includes three main categories and five subcategories, which is summarised in Table 1. 
Table 1 Categorisation of multiple attribute decision making (MADM) methods (Hwang and Yoon, 1981; Norris and Marshall, 1995; Yoon and Hwang, 1995; Xu and Yang, 2001; Kahraman, 2008; Wang et al., 2009c).

\begin{tabular}{|c|c|c|c|c|c|}
\hline \multicolumn{3}{|c|}{$\begin{array}{l}\text { Multiple attribute decision making (MADM) } \\
\text { methods }\end{array}$} & \multirow{2}{*}{ Purpose } & \multirow{2}{*}{$\begin{array}{l}\text { Evaluation approach } \\
\text { of the alternatives }\end{array}$} & \multirow{2}{*}{$\begin{array}{c}\text { Information required } \\
\text { beyond decision } \\
\text { matrix } \\
\text { about the attributes } \\
\text { (Note } 2 \text { ) }\end{array}$} \\
\hline Category & Subcategory & Methods & & & \\
\hline \multirow{7}{*}{ 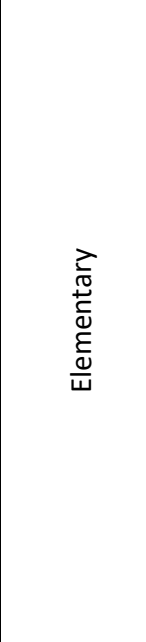 } & - & Dominance & Screening & Non-compensatory & None \\
\hline & \multirow{2}{*}{$\begin{array}{l}\text { Satisficing } \\
\text { methods }\end{array}$} & Conjunctive & Screening & Non-compensatory & \begin{tabular}{|c|} 
Minimum \\
performance for each \\
attribute
\end{tabular} \\
\hline & & Disjunctive & Screening & Non-compensatory & \begin{tabular}{|c|} 
Desirable \\
performance for each \\
attribute
\end{tabular} \\
\hline & \multirow{2}{*}{$\begin{array}{l}\text { Sequential } \\
\text { elimination } \\
\text { methods }\end{array}$} & Lexicographic & Ranking and choosing & Non-compensatory & $\begin{array}{l}\text { Ordinal importance } \\
\text { ranking }\end{array}$ \\
\hline & & $\begin{array}{l}\text { Elimination by } \\
\text { aspects }\end{array}$ & choosing & Non-compensatory & $\begin{array}{c}\text { Ordinal importance } \\
\text { ranking and minimum } \\
\text { performance }\end{array}$ \\
\hline & \multirow{2}{*}{$\begin{array}{l}\text { Attitude oriented } \\
\text { methods }\end{array}$} & Maximin & Ranking and choosing & Non-compensatory & None \\
\hline & & Maximax & Ranking and choosing & Non-compensatory & None \\
\hline \multirow{2}{*}{ 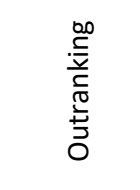 } & & ELECTRE & $\begin{array}{l}\text { Screening, ranking } \\
\text { and choosing }\end{array}$ & $\begin{array}{l}\text { Non-compensatory } \\
\text { (Note 1) }\end{array}$ & $\begin{array}{l}\text { Cardinal importance } \\
\quad \text { (weights) }\end{array}$ \\
\hline & & PROMETHEE & $\begin{array}{l}\text { Screening, ranking } \\
\text { and choosing }\end{array}$ & Non-compensatory & $\begin{array}{l}\text { Cardinal importance } \\
\text { (weights) }\end{array}$ \\
\hline \multirow{7}{*}{ 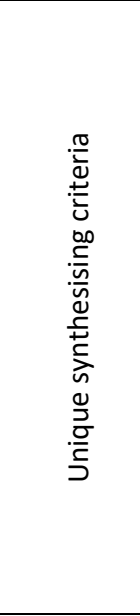 } & \multirow{2}{*}{$\begin{array}{l}\text { Compromising } \\
\text { methods }\end{array}$} & TOPSIS & $\begin{array}{l}\text { Screening, ranking } \\
\text { and choosing }\end{array}$ & Compensatory & $\begin{array}{l}\text { Cardinal importance } \\
\text { (weights) }\end{array}$ \\
\hline & & VIKOR & $\begin{array}{l}\text { Screening, ranking } \\
\text { and choosing }\end{array}$ & Compensatory & $\begin{array}{l}\text { Cardinal importance } \\
\text { (weights) }\end{array}$ \\
\hline & \multirow{5}{*}{$\begin{array}{l}\text { Scoring } \\
\text { methods }\end{array}$} & $\begin{array}{l}\text { Simple additive } \\
\text { weight }\end{array}$ & $\begin{array}{l}\text { Screening, ranking } \\
\text { and choosing }\end{array}$ & Compensatory & $\begin{array}{l}\text { Cardinal importance } \\
\text { (weights) }\end{array}$ \\
\hline & & Weight product & $\begin{array}{l}\text { Screening, ranking } \\
\text { and choosing }\end{array}$ & Compensatory & $\begin{array}{c}\text { Cardinal importance } \\
\text { (weights) }\end{array}$ \\
\hline & & Median ranking & $\begin{array}{l}\text { Screening, ranking } \\
\text { and choosing }\end{array}$ & Compensatory & $\begin{array}{c}\text { Cardinal importance } \\
\text { (weights) }\end{array}$ \\
\hline & & $\mathrm{AHP}$ & $\begin{array}{l}\text { Screening, ranking } \\
\text { and choosing }\end{array}$ & Compensatory & $\begin{array}{l}\text { Cardinal importance } \\
\text { (weights) }\end{array}$ \\
\hline & & Fuzzy & $\begin{array}{l}\text { Screening, ranking } \\
\text { and choosing }\end{array}$ & Compensatory & $\begin{array}{c}\text { Linguistic importance } \\
\text { (weights) }\end{array}$ \\
\hline \multicolumn{6}{|l|}{ Notes: } \\
\hline \multicolumn{6}{|c|}{$\begin{array}{l}\text { While the ELECTRE is principally a non-compensatory method (Roy, 1996; Mundam, 2005; Milani et al., 2006), } \\
\text { a few references consider it as a compensatory method (Hwang and Yoon, 1981). This disagreement has been } \\
\text { discussed by Bouyssou (1986). } \\
\text { Decision matrix: A MADM problem can be generally characterised by a 'decision matrix'. The decision matrix } \\
\text { demonstrates both the set of alternatives and the set of attributes being considered in a given problem. This } \\
\text { matrix provides the 'raw' data to the decision maker at the beginning of a decision making process. In a decision } \\
\text { matrix, each row/column corresponds to one alternative/attribute. In other words, a problem with ' } m \text { ' } \\
\text { alternatives characterised by ' } n \text { ' attributes is described by an m by } n \text { matrix. Each element of the matrix is the } \\
\text { 'score' or 'performance rating' or 'preference' of that row's alternative with respect to that column's attribute, } \\
\text { which can be stated either numerically or verbally (Norris and Marshall, 1995; Yoon and Hwang, 1995). }\end{array}$} \\
\hline
\end{tabular}


Among the methods shown in Table 1, non-compensatory methods are not able to make a trade-off between the high and the low performance attributes of alternatives and disadvantages of one attribute cannot be compensated for by the advantages of any other attribute. Using non-compensatory methods, an alternative with low performance in one attribute might be discarded from the decision process even if very high performance are evident in other attributes. However, the non-compensatory methods are credited for their simple logic and computation process (Yoon and Hwang, 1995). Conversely, the compensatory methods are more complex in terms of their logic and required computation process. Using the compensatory methods guaranties that an alternative with a slightly low performance in one attribute could still perform acceptably. In such cases, compensation between low and high performance attributes offers a more inclusive decision making by using the aggregated and compensated performance of alternatives with respect to all the attributes. In other words, by using compensatory methods the alternatives with a slightly lower performance in some attributes but a higher performance in others, are not discarded from the decision making process. This theoretically increases the chance of choosing the best alternative.

In this study a compensatory MADM method is a reasonable choice for the aggregated analysis between the alternatives due to the inherent compensatory ability of the method. However, uncertainty and imprecision are of the nature of decision making that should be also considered in the selection of any decision making method. Overall, 'MADM is a qualitative approach due to the existence of criteria subjectivity' (Ribeiro, 1996). In other words, except for the MADM methods such as, 'Dominance', 'Maximin' and 'Maximax' methods, compensatory MADM methods require further information beyond the decision matrix about the subjective importance of attributes as qualitative values. In addition, in many cases, the performance of each alternative is evaluated qualitatively in MADM methods. The uncertainty and imprecision in MADM methods mainly lie in the way that this qualitative information is quantified (Ribeiro, 1996; Wang et al., 2009c). In the sixth column of Table 1, all of the compensatory MADM, except the 'fuzzy' method, the subjective preference of the attributes are to be quantified and provided in cardinal crisp numbers (Saaty, 1990). However, in reality, the cardinal crisp preference scales are associated with 
uncertainty and impression; for example, the vagueness of human perception about linguistic terms such as 'important', 'more important', 'very important', and 'strongly more important'. It is recognised that the human judgment on the qualitative evaluation of alternatives with respect to each attribute and also the prioritisation of attributes within a decision making process is always subjective and originally expressed in linguistic scales (Kahraman, 2008; Wang et al., 2009c). Therefore, it is very difficult to dedicate a set of cardinal numbers to a set of relative linguistic terms expressing their right meaning (Wang et al., 2009c).

In this environment, the fuzzy set theory introduced by Zadeh (1965) is able to resolve this problem by adopting fuzzy numbers instead of crisp cardinal numbers wherever it is needed to transfer a linguistic preference scale to a numerical analysis (Kahraman, 2008; Wang et al., 2009c). It is worth mentioning that the fuzzy approach has been successfully applied in many decision making problems (Mamlook et al., 2001a; Mamlook et al., 2001b; Doukas et al., 2007; BenSalah et al., 2008; Lee et al., 2008; Wang et al., 2008a; Wang et al., 2008c; Wang et al., 2009a; Xu and Zhao, 2016).

Therefore, due to the ability of the fuzzy approach on dealing with uncertainty and imprecisions associated with multiple attribute decision making, the fuzzy approach is adopted in this study to conduct a formal decision making for HVAC\&R systems selection. The principal feature of the fuzzy set theory and the mathematical approach related to the fuzzy MADM method are described in the following sections.

\section{Research Design}

In order to develop a decision making model for the selection of HVAC\&R systems for office buildings, firstly, the authors developed a set of reference office buildings as being representative of the existing office building stock in the UK (Shahrestani et al., 2014). From among them, a reference office building has been selected for the study reported in this paper. Then, a set of alternative HVAC\&R systems has been identified to be investigated. The alternative HVAC\&R systems are theoretically installed in the reference office building and their technical and economic performance and environmental impacts are assessed using the TRNSYS software, version 17 (Klein et al., 2009) together with an estimation of the initial, operational and on-going maintenance costs. The detailed specification of the prototypical 
building and the numerical simulation of the different HVAC\&R systems are described in Shahrestani et al. (2013). Here, it should be noted that HVAC\&R systems are designed to match the cooling and heating loads calculated by TRNSYS. The control strategies for systems are based on standard practice addressed in CIBSE (2009), ASHRAE (2016) and ASHRAE (2015) to provide acceptable thermal comfort and indoor air quality. Finally, in order to select the most appropriate system from the alternative HVAC\&R systems a fuzzy multiple attribute decision making method is developed. Figure 1 shows the proposed model for HVAC\&R systems selection.

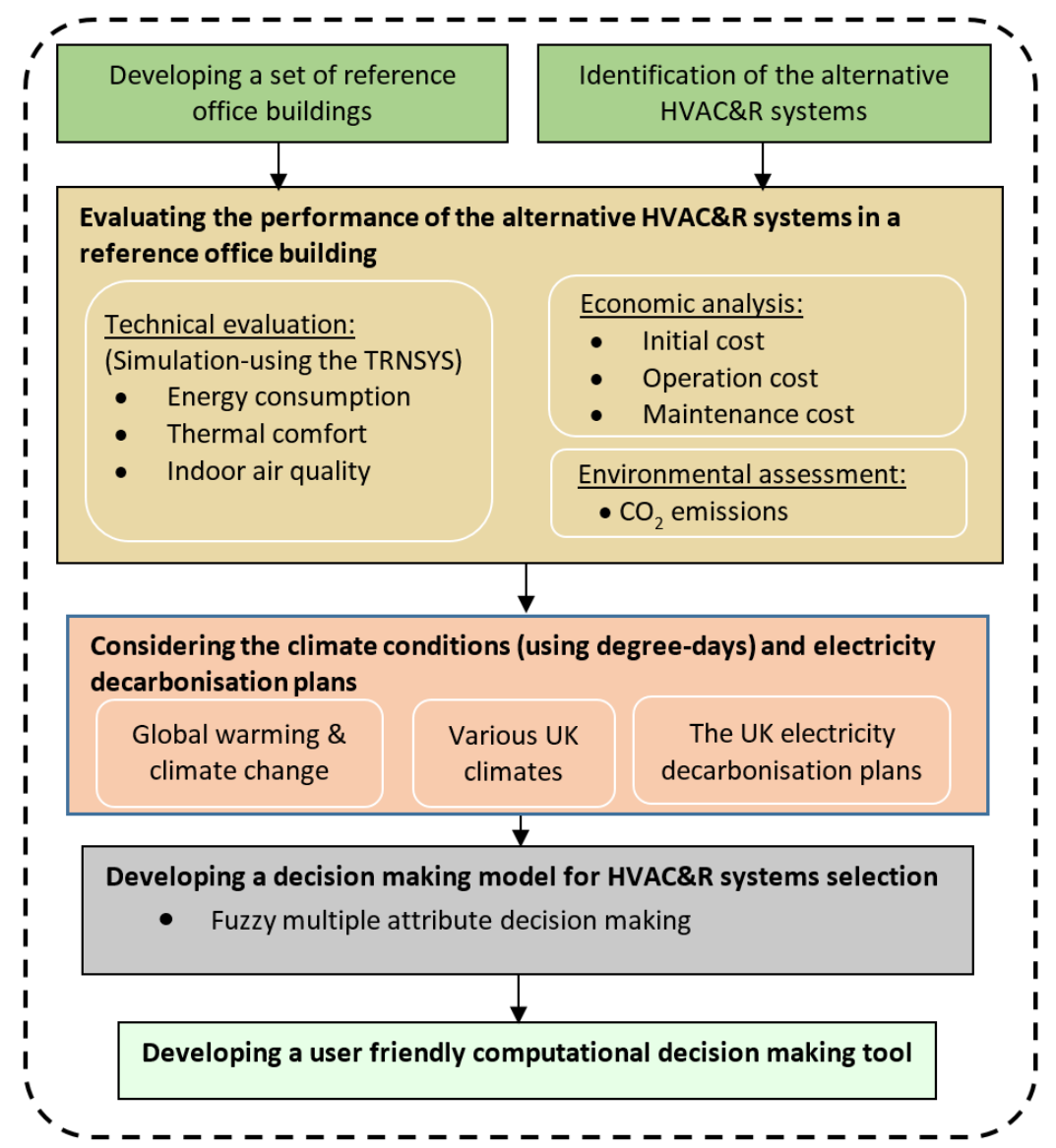

Figure 1 HVAC\&R systems selection model.

The systems selection model uses the London weather condition data. To extend the scope of study to other regions with different weather conditions in the UK, the degree-days theory (CIBSE-TM41, 2006) has been adopted. In addition, the degree-days theory is used to evaluate the future energy demands of the alternative HVAC\&R systems considering climate change and global warming effects (Murphy et al., 2009). Also, the UK Government's electricity decarbonisation plans (HM Government, 2009) are integrated to the decision making model. 
Finally, in order to make the decision making model applicable not only for researchers but also for designers and decision makers, the model is transferred into a computational tool with a user-friendly interface developed through Matlab package. The process of decision making is shown in Figure 2.

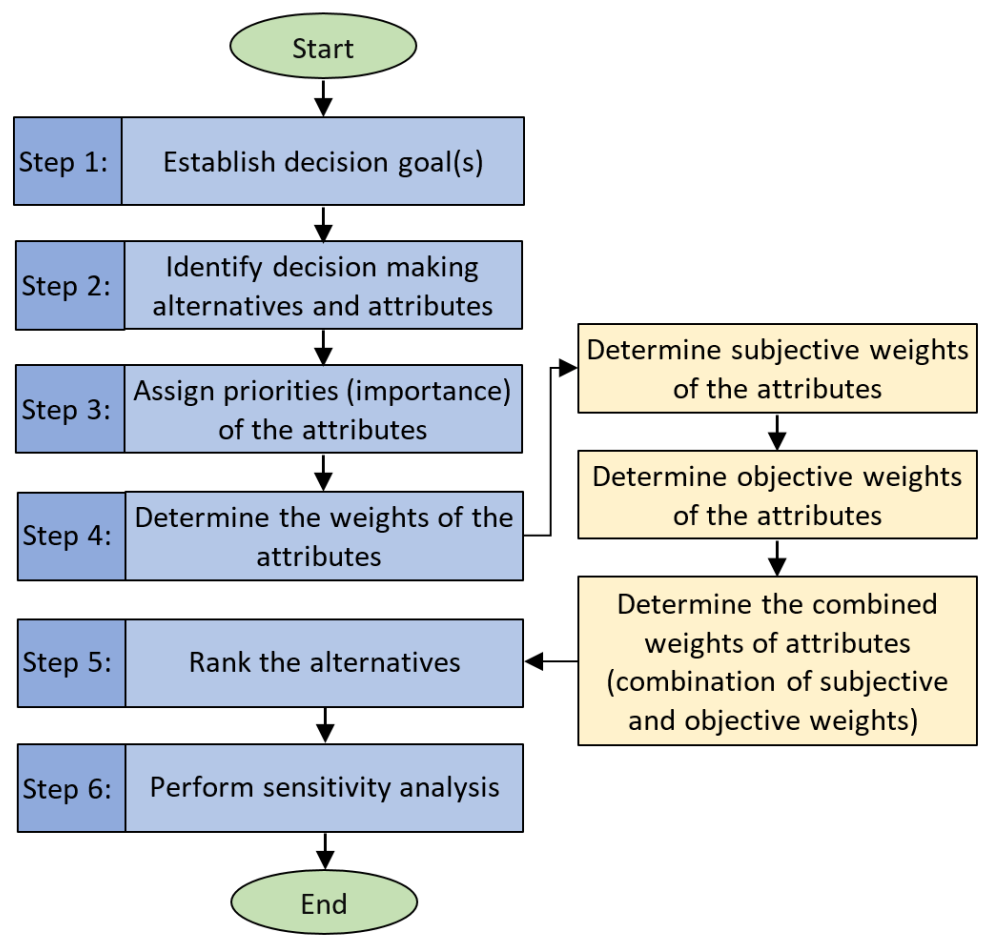

Figure 2 The decision making process adopted in this study.

\section{A Fuzzy MADM approach adopted in this study}

As explained in Section 2, due to the ability of fuzzy decision making to deal with linguistic terms, this method has been selected for decision making for HVAC\&R systems selection in this study. The detailed descriptions related to each step of the decision making process shown in Figure 2, are provided in the following subsections.

\subsection{Step 1: Establish decision goal(s)}

The decision making process comprises six main steps. The first step is to establish the decision goal(s). In this study, the main goal is to choose the most appropriate HVAC\&R system from among the alternative systems by the consideration of their various attributes. 


\subsection{Step 2: Identify decision making alternatives and attributes}

In the second step, as Figure 2, a review of the UK office building stock and previous studies outsides the UK in the Europe and US, as well as HVAC\&R systems market studies reveal that types of HVAC\&R systems, their occurrence and distribution in stock level are a real grey area in non-domestic building studies (Huang et al., 1991; Brigges et al., 1992; Pout et al., 1998; Rickaby and Gorgolewski, 2000; Torcellini et al., 2008; Knight et al., 2010). In other words, there is insufficient accurate evidence to identify the most common HVAC\&R systems installed in the UK office building stock. However, the most recently available distribution of HVAC\&R systems in office building stock provided by the NDBS project (Gakovic, 2000) and the most detailed European survey on HVAC\&R systems (HARMONAC) conducted by Knight et al. (2010) provide an insight into the type and distribution of HVAC\&R systems in the UK and Europe. Most of HVAC\&R systems surveyed within these two sources are considered as alternatives for HVAC\&R systems selection in this study. In addition, HVAC\&R systems that are identified as good examples of energy-efficiency measures towards carbon reduction targets introduced in DCLG (2007) have also been included in the list of alternative HVAC\&R systems considered in this study. The primary and secondary parts of these alternative HVAC\&R systems are respectively demonstrated in Table 2 and Table 3. Taking into account the applicable combinations of primary heating and cooling systems shown in Table 2 and secondary systems provided in Table 3 forms the main alternative HVAC\&R systems, which are investigated in this study. These alternative systems are categorised based on their principal attributes, e.g. centralised air systems, partially centralised and local systems, as well as primary and secondary parts as shown in Table 4. Also, six attributes of these alternative systems, which have been placed within three categories, are identified and included in the decision making process. These attributes are introduced in Table 5.

Table 2 Primary parts of the alternative HVAC\&R systems considered in the decision making process for HVAC\&R systems selection in this study.

\begin{tabular}{|l|l|}
\hline \multicolumn{2}{|c|}{ Primary parts of the alternative HVAC\&R systems } \\
\hline 1 & Vapour compression air cooled chiller with gas boiler \\
\hline 2 & Absorption chiller (direct fire) with gas boiler \\
\hline 3 & Combined heat and power (CHP) with hot water absorption chiller (CCHP) \\
\hline 4 & Ground coupled heat pump (GCHP) \\
\hline
\end{tabular}


Table 3 Secondary parts of the alternative HVAC\&R systems considered in the decision making process for HVAC\&R systems selection in this study.

\begin{tabular}{|c|l|}
\hline \multicolumn{2}{|c|}{ Secondary parts of the alternative HVAC\&R systems } \\
\hline 1 & Constant Air Volume (CAV) system \\
\hline 2 & Variable Air Volume (VAV) system \\
\hline 3 & CAV system with heat recovery \\
\hline 4 & VAV system with heat recovery \\
\hline 5 & CAV system with economiser \\
\hline 6 & VAV system with economiser \\
\hline 7 & Constant Air Volume (CAV) system with reheat \\
\hline 8 & Variable Air Volume (VAV) system with reheat \\
\hline 9 & CAV system with heat recovery and reheat \\
\hline 10 & VAV system with heat recovery and reheat \\
\hline 11 & CAV system with economiser and reheat \\
\hline 12 & VAV system with economiser and reheat \\
\hline 13 & Fan coil with dedicated outdoor air system - CAV air distribution system with heat recovery \\
\hline 14 & Fan coil with dedicated outdoor air system - CAV air distribution system \\
\hline 15 & All water fan coil system \\
\hline
\end{tabular}

Table 4 Categorisation of the alternative HVAC\&R systems considered in the decision making process for HVAC\&R systems selection in this study.

\begin{tabular}{|c|c|c|c|c|c|c|}
\hline \multirow{2}{*}{ No. } & \multicolumn{2}{|c|}{ Primary system (main parts) } & \multicolumn{3}{|c|}{ Secondary systems (main parts) } & \multirow{2}{*}{$\begin{array}{l}\text { Principal } \\
\text { category }\end{array}$} \\
\hline & Heating & Cooling & Part1 & Part 2 & Part 3 & \\
\hline 1 & \multirow{12}{*}{ Gas boiler } & \multirow{12}{*}{$\begin{array}{l}\text { Vapour compression } \\
\text { air cooled chiller }\end{array}$} & CAV & - & - & \multirow{6}{*}{$\begin{array}{c}\text { Centralised } \\
\text { (all-air) } \\
\text { systems }\end{array}$} \\
\hline 2 & & & VAV & - & - & \\
\hline 3 & & & CAV & Heat recovery & - & \\
\hline 4 & & & VAV & Heat recovery & - & \\
\hline 5 & & & CAV & Economiser & - & \\
\hline 6 & & & VAV & Economiser & - & \\
\hline 7 & & & CAV & - & Reheat & \multirow{6}{*}{$\begin{array}{c}\text { Partially } \\
\text { centralise } \\
\text { (air-water) } \\
\text { systems }\end{array}$} \\
\hline 8 & & & VAV & - & Reheat & \\
\hline 9 & & & CAV & Heat recovery & Reheat & \\
\hline 10 & & & VAV & Heat recovery & Reheat & \\
\hline 11 & & & CAV & Economiser & Reheat & \\
\hline 12 & & & VAV & Economiser & Reheat & \\
\hline 13 & \multirow{12}{*}{ Gas boiler } & \multirow{12}{*}{$\begin{array}{c}\text { Direct fire } \\
\text { absorption chiller }\end{array}$} & CAV & - & - & \multirow{6}{*}{$\begin{array}{c}\text { Centralised } \\
\text { (all-air) } \\
\text { systems }\end{array}$} \\
\hline 14 & & & VAV & - & - & \\
\hline 15 & & & CAV & Heat recovery & - & \\
\hline 16 & & & VAV & Heat recovery & - & \\
\hline 17 & & & CAV & Economiser & - & \\
\hline 18 & & & VAV & Economiser & - & \\
\hline 19 & & & CAV & - & Reheat & \multirow{6}{*}{$\begin{array}{c}\text { Partially } \\
\text { centralise } \\
\text { (air-water) } \\
\text { systems }\end{array}$} \\
\hline 20 & & & VAV & - & Reheat & \\
\hline 21 & & & CAV & Heat recovery & Reheat & \\
\hline 22 & & & VAV & Heat recovery & Reheat & \\
\hline 23 & & & CAV & Economiser & Reheat & \\
\hline 24 & & & VAV & Economiser & Reheat & \\
\hline
\end{tabular}




\begin{tabular}{|c|c|c|c|c|c|c|}
\hline \multirow{2}{*}{ No. } & \multicolumn{2}{|c|}{ Primary system (main parts) } & \multicolumn{3}{|c|}{ Secondary systems (main parts) } & \multirow{2}{*}{$\begin{array}{l}\text { Principal } \\
\text { category }\end{array}$} \\
\hline & Heating & Cooling & Part1 & Part 2 & Part 3 & \\
\hline 25 & \multirow{12}{*}{$\begin{array}{c}\text { Gas boiler with } \\
\text { CHP unit }\end{array}$} & \multirow{12}{*}{$\begin{array}{c}\text { CHP unit with hot } \\
\text { water absorption } \\
\text { chiller }\end{array}$} & CAV & - & - & \multirow{6}{*}{$\begin{array}{l}\text { Centralised } \\
\text { (all-air) } \\
\text { systems }\end{array}$} \\
\hline 26 & & & VAV & - & - & \\
\hline 27 & & & CAV & Heat recovery & - & \\
\hline 28 & & & VAV & Heat recovery & - & \\
\hline 29 & & & CAV & Economiser & - & \\
\hline 30 & & & VAV & Economiser & - & \\
\hline 31 & & & CAV & - & Reheat & \multirow{6}{*}{$\begin{array}{c}\text { Partially } \\
\text { centralise } \\
\text { (air-water) } \\
\text { systems }\end{array}$} \\
\hline 32 & & & VAV & - & Reheat & \\
\hline 33 & & & CAV & Heat recovery & Reheat & \\
\hline 34 & & & VAV & Heat recovery & Reheat & \\
\hline 35 & & & CAV & Economiser & Reheat & \\
\hline 36 & & & VAV & Economiser & Reheat & \\
\hline 37 & \multirow{12}{*}{$\begin{array}{l}\text { Ground coupled } \\
\text { heat pump } \\
(\mathrm{GCHP})\end{array}$} & \multirow{12}{*}{$\begin{array}{l}\text { Ground coupled } \\
\text { heat pump } \\
(\mathrm{GCHP})\end{array}$} & CAV & - & - & \multirow{6}{*}{$\begin{array}{l}\text { Centralisec } \\
\text { (all-air) } \\
\text { systems }\end{array}$} \\
\hline 38 & & & VAV & - & - & \\
\hline 39 & & & CAV & Heat recovery & - & \\
\hline 40 & & & VAV & Heat recovery & - & \\
\hline 41 & & & CAV & Economiser & - & \\
\hline 42 & & & VAV & Economiser & - & \\
\hline 43 & & & CAV & - & Reheat & \multirow{6}{*}{$\begin{array}{c}\text { Partially } \\
\text { centralise } \\
\text { (air-water) } \\
\text { systems }\end{array}$} \\
\hline 44 & & & VAV & - & Reheat & \\
\hline 45 & & & CAV & Heat recovery & Reheat & \\
\hline 46 & & & VAV & Heat recovery & Reheat & \\
\hline 47 & & & CAV & Economiser & Reheat & \\
\hline 48 & & & VAV & Economiser & Reheat & \\
\hline 49 & Gas boiler & $\begin{array}{c}\text { Vapour compression } \\
\text { air cooled chiller }\end{array}$ & CAV-DOAS & Heat recovery & Fan coil & \multirow{9}{*}{$\begin{array}{c}\text { Partially } \\
\text { centralise } \\
\text { (air-water) } \\
\text { systems }\end{array}$} \\
\hline 50 & Gas boiler & $\begin{array}{c}\text { Direct fire } \\
\text { absorption chiller }\end{array}$ & CAV-DOAS & Heat recovery & Fan coil & \\
\hline 51 & $\begin{array}{c}\text { Gas boiler with } \\
\text { CHP unit }\end{array}$ & $\begin{array}{l}\text { CHP with hot water } \\
\text { absorption chiller }\end{array}$ & CAV-DOAS & Heat recovery & Fan coil & \\
\hline 52 & Gas boiler & $\begin{array}{l}\text { Vapour compression } \\
\text { air cooled chiller }\end{array}$ & CAV-DOAS & - & Fan coil & \\
\hline 53 & Gas boiler & $\begin{array}{c}\text { Direct fire } \\
\text { absorption chiller }\end{array}$ & CAV-DOAS & - & Fan coil & \\
\hline 54 & $\begin{array}{c}\text { Gas boiler with } \\
\text { CHP unit }\end{array}$ & $\begin{array}{l}\text { CHP with hot water } \\
\text { absorption chiller }\end{array}$ & CAV-DOAS & - & Fan coil & \\
\hline 55 & Gas boiler & $\begin{array}{c}\text { Vapour compression } \\
\text { air cooled chiller }\end{array}$ & - & - & Fan coil & \\
\hline 56 & Gas boiler & $\begin{array}{c}\text { Direct fire } \\
\text { absorption chiller }\end{array}$ & - & - & Fan coil & \\
\hline 57 & $\begin{array}{c}\text { Gas boiler with } \\
\text { CHP unit }\end{array}$ & $\begin{array}{l}\text { CHP with hot water } \\
\text { absorption chiller }\end{array}$ & - & - & Fan coil & \\
\hline 58 & \multicolumn{5}{|c|}{ local packaged air conditioning unit (split air source heat pump unit) } & $\begin{array}{c}\text { Local } \\
\text { systems }\end{array}$ \\
\hline
\end{tabular}


Table 5 Attributes of the alternative HVAC\&R systems considered in this study.

\begin{tabular}{|c|c|c|}
\hline Category & Attributes & Assessment method \\
\hline \multirow{3}{*}{ Technical performance } & Energy consumption & Numerical simulation \\
\cline { 2 - 3 } & Thermal comfort -PMV method (BS/ISO:7730, 2005) & Numerical simulation \\
\cline { 2 - 3 } & Indoor air quality (CO, concentration) & Numerical simulation \\
\hline \multirow{2}{*}{ Economic aspects } & Initial cost & Cost estimation \\
\cline { 2 - 3 } & Variable (operational) cost & Cost estimation \\
\hline \multirow{2}{*}{ Environment impacts } & $\mathrm{CO}_{2}$ emissions & Numerical simulation \\
\hline
\end{tabular}

As mentioned in Table 5, initial and variable (operational) costs are considered in the decision making process. The initial cost of the HVAC\&R systems is estimated based on the cost data provided by Davis Langdon (2016). In addition, to estimate the initial cost, the regional cost factors/indices suggested by Davis Langdon (2016) are considered for different regions in the UK (Figure 4).

To estimate the operation cost, both the utility and maintenance costs are taken into account. The energy cost is estimated based on the outcome of simulation of the energy performance of alternative systems using TRNSYS software. The maintenance cost of the system is determined based on the expected life time of the systems provided by ASHRAE (2013), CIBSE (2008) and Abramson et al. (2005). The energy consumption and cost associated with alternative systems are reported in Shahrestani et al. (2013) and Shahrestani (2013).

After defining the decision making goal, the various alternatives and attributes, the hierarchical structure of the decision making process for HVAC\&R systems selection is established and demonstrated in Figure 3.

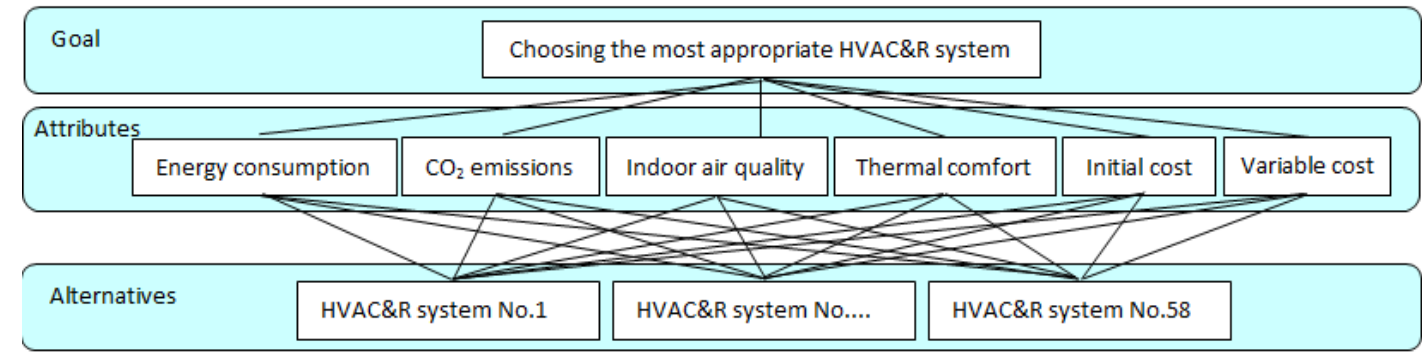

Figure 3 The hierarchical structure of the decision making process for HVAC\&R systems selection. 


\subsubsection{Additional parameters involved in decision making}

In the previous section, six attributes of HVAC\&R systems that are considered in this MADM study were described in Table 5. However, those attributes are highly influenced by external and system non-related conditions including, the location of the building, climate change issues and the UK government plan for the decarbonisation of electricity. In this study, the influence of all the aforementioned conditions are taken into account.

The energy consumption of 58 alternative HVAC\&R systems simulated for London weather conditions were extended to a) the 18 regions of the UK, see Figure 4 and b) the future using future weather projection, Table 6, (Murphy et al., 2009) and the degree-days weather adjustment approach (CIBSE-TM41, 2006). Eighteen regions in the UK together with two climate change emissions scenarios of medium and high emissions, each in 5 probability percentile levels $(10 \%, 33 \%, 50 \%, 66 \%$, and $90 \%)$; were considered in the degree-days weather adjustment approach used to estimate the energy consumption of the alternative HVAC\&R systems (Murphy et al., 2009). In addition, to evaluate the energy related $\mathrm{CO}_{2}$ emissions of the alternative HVAC\&R systems, the UK government plan on electricity decarbonisation (MARKAL) is considered in the decision making process (HM Government, 2009).

MARKAL (acronym for MARKet ALlocation) model is a dynamic energy optimisation model to optimise the total cost of energy systems simultaneously with mitigation of the $\mathrm{CO}_{2}$ emissions to at least 80\% below 1990 levels by 2050 (DECC, 2009; HM Government, 2009). The MARKAL model is particularly useful in exploring energy systems in the long-term (DECC, 2009). In this study, eight electricity decarbonisation plans provided by the UK MARKAL model (HM Government, 2009) are used to analyse long term, through-life, $\mathrm{CO}_{2}$ emissions of the alternative HVAC\&R systems. The MARKAL scenarios for electricity decarbonisation in the UK are shown in Figure 5 and Table 7. 


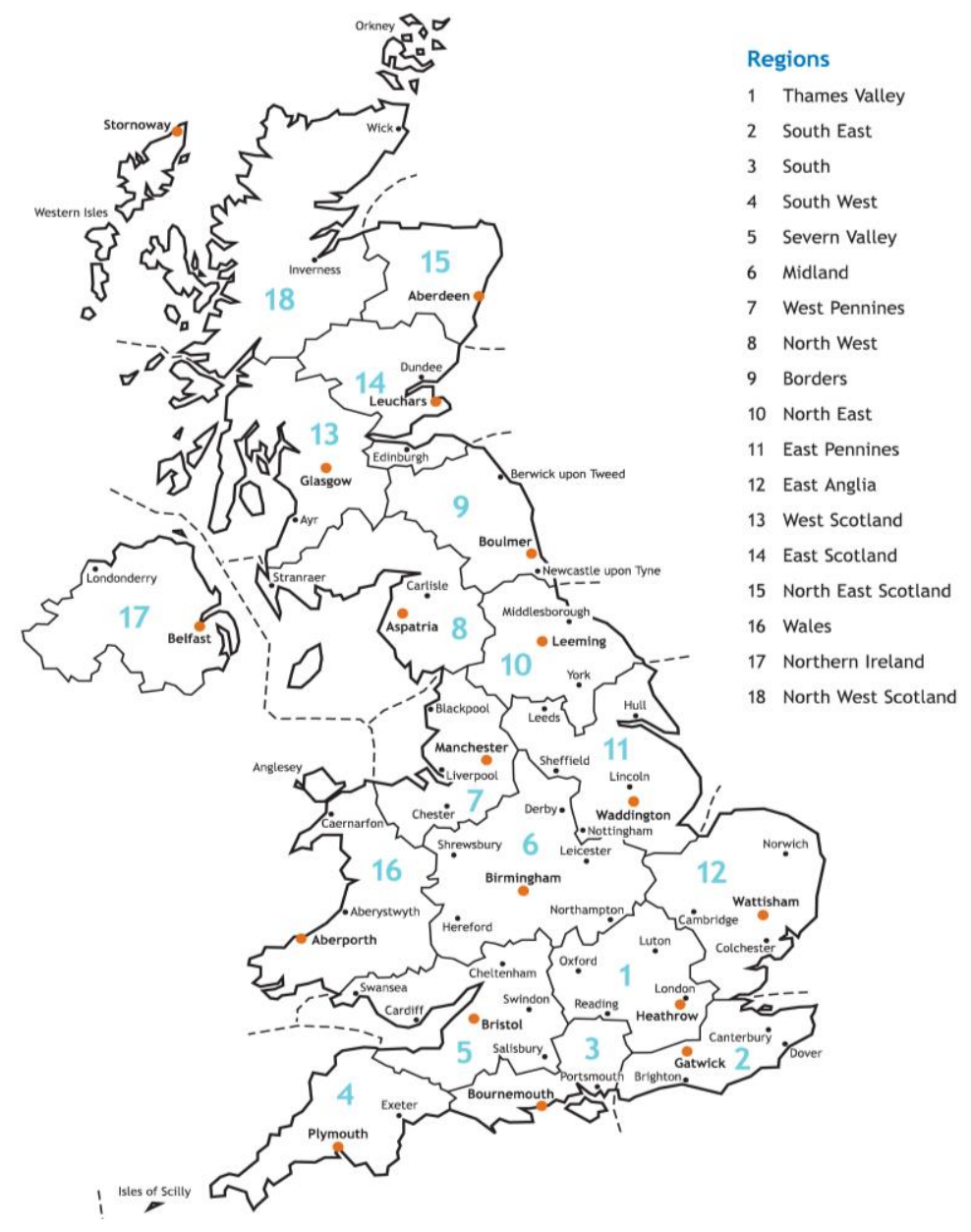

Figure 4 Degree-days regions in the UK (CT, 2007).

Table 6 The highest and lowest changes in mean daily temperature, mean daily maximum temperature and mean daily minimum temperature in winter and summer by the 2080s, relative to 1961-1990 (Murphy et al., 2009).

\begin{tabular}{|c|c|c|c|c|c|c|c|c|c|c|c|c|c|c|c|c|c|c|c|}
\hline \multirow{2}{*}{\multicolumn{2}{|c|}{\begin{tabular}{|c|} 
Variable \\
Probability level
\end{tabular}}} & \multicolumn{3}{|c|}{$\begin{array}{c}\text { Mean } \\
\text { temperature } \\
\text { winter }\left({ }^{\circ} \mathrm{C}\right)\end{array}$} & \multicolumn{3}{|c|}{$\begin{array}{c}\text { Mean } \\
\text { temperature } \\
\text { summer }\left({ }^{\circ} \mathrm{C}\right)\end{array}$} & \multicolumn{3}{|c|}{$\begin{array}{l}\text { Mean daily } \\
\text { maximum } \\
\text { temperature } \\
\text { winter }\left({ }^{\circ} \mathrm{C}\right)\end{array}$} & \multicolumn{3}{|c|}{$\begin{array}{l}\text { Mean daily } \\
\text { maximum } \\
\text { temperature } \\
\text { summer }\left({ }^{\circ} \mathrm{C}\right)\end{array}$} & \multicolumn{3}{|c|}{$\begin{array}{l}\text { Mean daily } \\
\text { minimum } \\
\text { temperature } \\
\text { winter }\left({ }^{\circ} \mathrm{C}\right)\end{array}$} & \multicolumn{3}{|c|}{$\begin{array}{l}\text { Mean daily } \\
\text { minimum } \\
\text { temperature } \\
\text { summer }\left({ }^{\circ} \mathrm{C}\right)\end{array}$} \\
\hline & & $10 \%$ & $50 \%$ & $90 \%$ & $10 \%$ & $50 \%$ & $90 \%$ & $10 \%$ & $50 \%$ & $90 \%$ & $10 \%$ & $50 \%$ & $90 \%$ & $10 \%$ & $50 \%$ & $90 \%$ & $10 \%$ & $50 \%$ & $90 \%$ \\
\hline \multirow{2}{*}{$\begin{array}{c}\text { High } \\
\text { emission }\end{array}$} & $\begin{array}{c}\text { Highest } \\
\text { change } \\
\text { in UK }\end{array}$ & 2.2 & 3.8 & 5.8 & 2.9 & 5.3 & 8.4 & 1.6 & 3.4 & 6.1 & 3.0 & 6.8 & 11.7 & 2.0 & 4.2 & 7.0 & 2.8 & 5.3 & 8.8 \\
\hline & $\begin{array}{l}\text { Lowest } \\
\text { change } \\
\text { in UK }\end{array}$ & 1.0 & 2.1 & 3.5 & 1.6 & 3.1 & 5.0 & 1.1 & 2.3 & 3.9 & 1.2 & 3.5 & 6.3 & 0.8 & 2.4 & 4.3 & 1.7 & 3.3 & 5.6 \\
\hline \multirow{2}{*}{$\begin{array}{l}\text { Medium } \\
\text { emission }\end{array}$} & $\begin{array}{c}\text { Highest } \\
\text { change } \\
\text { in UK }\end{array}$ & 1.7 & 3.1 & 4.8 & 2.2 & 4.2 & 6.8 & 1.3 & 2.9 & 5.1 & 2.2 & 5.4 & 9.5 & 1.5 & 3.5 & 5.9 & 2.0 & 4.1 & 7.1 \\
\hline & $\begin{array}{c}\text { Lowest } \\
\text { change } \\
\text { in UK } \\
\end{array}$ & 0.8 & 1.8 & 3.1 & 1.2 & 2.5 & 4.1 & 0.8 & 2.0 & 3.4 & 1.1 & 2.8 & 5.0 & 0.6 & 2.1 & 3.7 & 1.3 & 2.7 & 4.5 \\
\hline
\end{tabular}




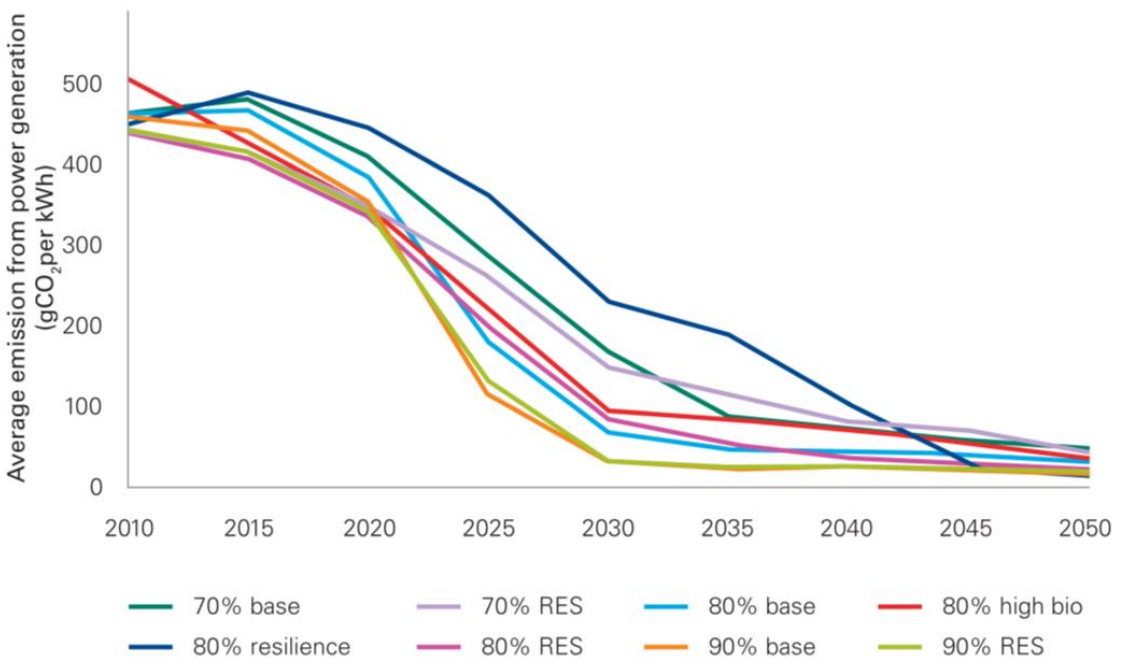

Figure 5 Rate of decarbonisation of the electricity under MARKAL scenarios (HM

Government, 2009).

Table 7 Description of the MARKAL scenarios for the UK electricity decarbonisation plan (HM Government, 2009).

\begin{tabular}{|c|c|c|}
\hline Scenarios & $\begin{array}{l}\text { CO2 Emissions reductions } \\
\text { (relative to 1990) }\end{array}$ & Assumptions \\
\hline $70 \%$ base & $\begin{array}{l}29 \% \text { in } 2020 \\
70 \% \text { in } 2050 .\end{array}$ & $\begin{array}{l}\text { Max nuclear and Carbon Capture and Storage (CCS) build rate } \\
3 \mathrm{GW} \text { p.a. in the } 2020 \text { s, } 5 \mathrm{GW} \text { p.a. thereafter. }\end{array}$ \\
\hline $70 \%$ RES & $\begin{array}{l}29 \% \text { in } 2020 \\
70 \% \text { in } 2050 .\end{array}$ & $\begin{array}{l}\text { Model constrained to deliver sufficient renewable generation } \\
\text { in } 2020 \text { to meet the renewable energy target. }\end{array}$ \\
\hline $80 \%$ base & $\begin{array}{l}33 \% \text { in } 2020 . \\
80 \% \text { in } 2050\end{array}$ & $\begin{array}{l}\text { Max nuclear and Carbon Capture and Storage (CCS) build rate } \\
3 \text { GW p.a. in the } 2020 \text { s, } 5 \text { GW p.a. thereafter. }\end{array}$ \\
\hline $\begin{array}{l}80 \% \text { high bio- } \\
\text { energy }\end{array}$ & $\begin{array}{l}31 \% \text { in } 2020 \\
80 \% \text { in } 2050 .\end{array}$ & $\begin{array}{l}\text { High availability of domestic and imported biomass, with high } \\
\text { capacity for biomass liquids to meet transport energy demand. }\end{array}$ \\
\hline $80 \%$ RES & $\begin{array}{l}29 \% \text { in } 2020, \\
80 \% \text { in } 2050 .\end{array}$ & $\begin{array}{l}\text { Model constrained to deliver sufficient renewable generation } \\
\text { in } 2020 \text { to meet the renewable energy target. }\end{array}$ \\
\hline $\begin{array}{l}80 \% \text { 'resilience' } \\
\text { (low electricity) }\end{array}$ & $\begin{array}{l}26 \% \text { in } 2020 \\
80 \% \text { in } 2050 .\end{array}$ & $\begin{array}{l}\text { Energy demand must fall by at least } 1.2 \% \text { a year. No single } \\
\text { energy source can account for }>40 \% \text { of the primary energy mix, } \\
\text { or more than } 40 \% \text { of the power mix from } 2015 \text { onwards. } \\
\text { Constraints on level of expected un-served energy. Power } \\
\text { sector modelling supplemented to account better for } \\
\text { intermittency. }\end{array}$ \\
\hline
\end{tabular}

\subsection{Step 3: Assign priorities (importance) of the attributes}

In the third step of the decision making process, see Figure 2, the priorities of the attributes are assigned. Using the fuzzy decision making approach, the priority of the attributes is assigned based on a set of linguistic scales. In the fuzzy set theory, fuzzy numbers, which are 
a subset of real numbers are used to represent the quantitative judgment of qualitative data. For example, ' $A$ ' is a triangular fuzzy number (TFN) if it has the following membership function:

$f_{A}(x)=\left\{\begin{array}{cc}1, & x=m \\ (x-1) /(m-l), & I \leq x \leq m \\ (r-x) /(r-m), & m<x<r \\ 0, & \text { otherwise }\end{array}\right.$

Where, 'I' and ' $r$ ' are respectively the lower and upper bounds of the fuzzy number ' $A$ ' and ' $m$ ' stands for the middle value as shown in Figure 6.

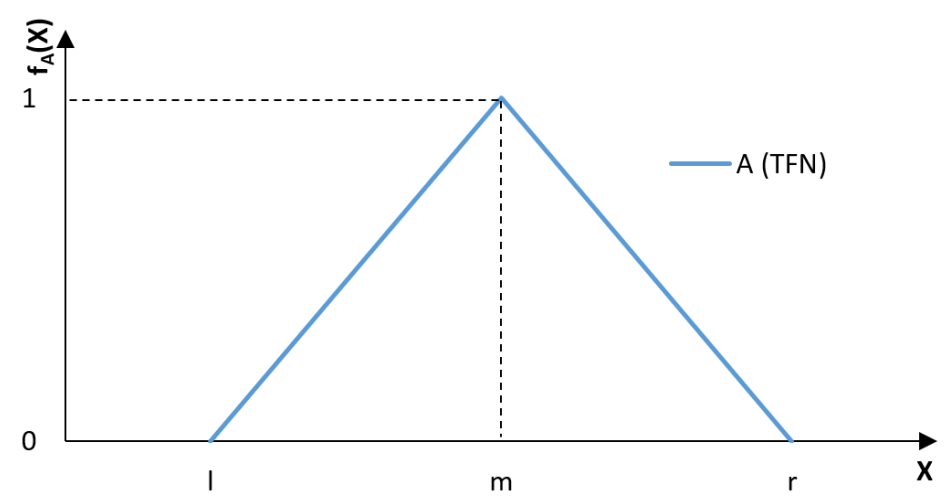

Figure 6 The membership function of a triangular fuzzy number (TFN) ' $A$ '.

As it is demonstrated in Figure 6 , a triangular fuzzy number (TFN) can be denoted by $A=(I, m$, $r)$. The operation laws for two TFNs; $A=\left(l_{a}, m_{a}, r_{a}\right)$ and $B=\left(l_{b}, m_{b}, r_{b}\right)$ are described in the following equations (Dubois and Prade, 1980; Bhowmik et al., 2008; Taylan et al., 2016):

$$
\begin{aligned}
& A+B=\left(I_{a}+I_{b}, m_{a}+m_{b}, r_{a}+r_{b}\right) \\
& A-B=\left(I_{a}-r_{b}, m_{a}-m_{b}, r_{a}-I_{b}\right) \\
& A \times B=\left(I_{a} \times I_{b}, m_{a} \times m_{b}, r_{a} \times r_{b}\right) \\
& A \div B=\left(I_{a} / r_{b}, m_{a} / m_{b}, r_{a} / I_{b}\right)
\end{aligned}
$$

In this study, the linguistic scales used to determine the relative importance of the attributes proposed by Wang et al. (2009a), Kahraman et al. (2006) and Wang et al. (2008c) have been adopted. These scales are shown in Table 8 and Figure 7. 
Table 8 The linguistic scales used to determine the relative importance of the attributes

(Wang et al., 2009a).

\begin{tabular}{|c|c|c|c|}
\hline Linguistic scales for importance & $\begin{array}{c}\text { Triangular } \\
\text { fuzzy scale }\end{array}$ & Linguistic scales for importance & $\begin{array}{c}\text { Triangular } \\
\text { fuzzy scale } \\
\text { (Reciprocal) }\end{array}$ \\
\hline Just equal (JE) & $(1,1,1)$ & Just equal (JE) & $(1,1,1)$ \\
\hline Weakly more important (WMI) & $(1,3 / 2,2)$ & Weakly less important (WLI) & $(1 / 2,2 / 3,1)$ \\
\hline Strongly more important (SMI) & $(3 / 2,2,5 / 2)$ & Strongly less important (SLI) & $(2 / 5,1 / 2,2 / 3)$ \\
\hline Very strongly more important (VSMI) & $(2,5 / 2,3)$ & Very strongly less important (VSLI) & $(1 / 3,2 / 5,1 / 2)$ \\
\hline Absolutely more important (AMI) & $(5 / 2,3,7 / 2)$ & Absolutely less important (ALI) & $(2 / 7,1 / 3,2 / 5)$ \\
\hline
\end{tabular}

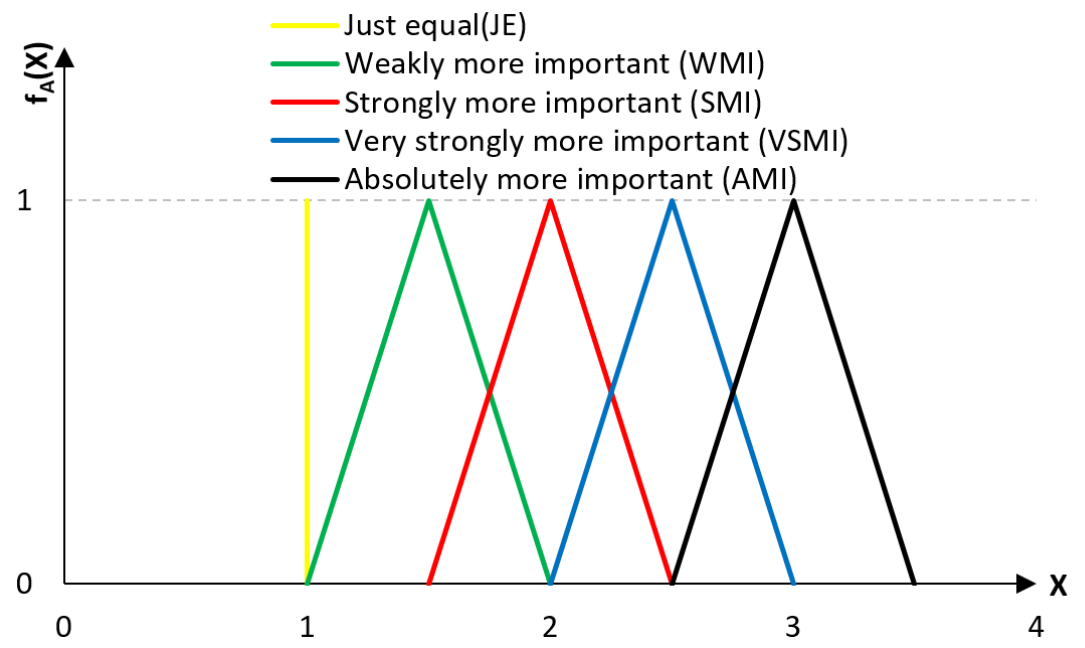

Figure 7 The linguistic scales for relative importance.

These linguistic scales are assigned in a pair-wise comparison manner to each pair of attributes by a decision maker and the outcomes of these comparisons are inserted into a pair-wise comparison matrix. Assuming there are ' $n$ ' attributes, the attributes pairwisecomparison matrix $(Q)$ is formed as follows:

$Q=\left[\begin{array}{cccc}q_{1,1}=A t t_{1} / A t t_{1} & q_{1,2}=A t t_{1} / A t t_{2} & \ldots & q_{1, n}=A t t_{1} / A t t_{n} \\ q_{2,1}=A t t_{2} / A t t_{1} & q_{2,2}=A t t_{2} / A t t_{2} & \ldots & q_{2, n}=A t t_{2} / A t t_{n} \\ \cdot & \cdot & \ldots & . \\ q_{n, 1}=A t t_{n} / A t_{1} & q_{n, 2}=A t t_{n} / A t t_{2} & \ldots & q_{n, n}=A t t_{n} / A t t_{n}\end{array}\right]_{n \times n}$

In this matrix, each element represents the relative preference of one attribute over another. For instance, the element in the first row and the second column ' $q_{1,2}=A t t_{1} / A_{t t}{ }_{2}$ represents the relative importance of the first attribute over the second attribute using the linguistic 
scales described in Table 8. This comparison matrix ' $Q$ ' will then be used in the next step, as figure 2 , to calculate the relative weight of each attribute in the decision making process.

\subsection{Step 4: Determine the weights of the attributes}

In MADM, weights are assigned to the attributes in order to consider the relative importance of each attribute to the final rank of the alternatives. Generally, the methods for weighting the attributes can be classified into two groups: 1- equal weighting, and 2-rank-order weighting methods (Jia et al., 1998; Wang et al., 2009c).

The equal weighting method allocates an identical weight to all attributes. Despite the simplicity of this method, Dawes and Corrigan (1974) have shown that this method can produce results which are 'nearly as good as' other rank-order weighting methods. However, ignoring the relative importance of attributes is of significant disadvantages of this method (Wang et al., 2009c). Alternatively, the rank-order weighting methods are able to accommodate the unequal preferences of attributes associated with alternatives. These methods are categorised into three clusters; subjective, objective and combination weighting methods (Wang et al., 2009c). The subjective weighting method is used to allocate the preference of the decision maker to the attributes of alternatives. Whereas, the objective weighting methods indicate the extent of the variations in the performance of alternatives across each attribute. Finally, the combination weighting methods are used to integrate both the subjective and the objective weights (Chatzimouratidis and Pilavachi, 2007; Wang et al., 2009b).

\subsubsection{Determine the subjective weights of the attributes}

In order to determine the subjective weights, the weight vector ' $Y$ ', is calculated using the geometric mean method (Buckley et al., 2001; Wang et al., 2008c; Wang et al., 2009a) according to the following equation:

$Y_{i}=\left[\prod_{j=1}^{n} q_{i, j}\right]^{1 / n}$, For $\mathrm{i}=1$ to $\mathrm{n}$ (number of attributes) 
Where, $q_{i, j}$ stands for the elements of the pair-wise comparison matrix of attributes described in Equation 6 and $n$ is the number of attributes. Then, the vector of fuzzy subjective weights $W^{s}$ is determined by the normalisation of the weight vector $Y$ according to the following equation (Wang et al., 2009a):

$W^{s}=\left[Y_{1} / \sum_{i=1}^{n} Y_{i}, Y_{2} / \sum_{i=1}^{n} Y_{i}, \ldots, Y_{n} / \sum_{i=1}^{n} Y_{i}\right]$

In the vector of fuzzy subjective weights $W^{s}$, the weights of each attribute is provided by a triangular fuzzy number (TFN). In this study, the graded mean integration representation method proposed by Chen and Hsieh (2000) is used to transfer these fuzzy weights to real numbers that represents the relative subjective weights of attributes according to the following equation:

$$
\begin{aligned}
& A=\left(I_{a}, m_{a}, r_{a}\right) \\
& R(A)=\frac{I_{a}+4 m_{a}+r_{a}}{6}
\end{aligned}
$$

Where, ' $A$ ' is a TFN and ' $R(A)$ ' is the graded mean integration representation of ' $A$ '. The relative relation between two TFNs ' $A$ ' and ' $B$ ' and their graded mean integration representations, ' $R(A)$ ' and ' $R(B)$ ' are shown as below:

$$
\begin{aligned}
& A>B \Leftrightarrow R(A)>R(B), \\
& A=B \Leftrightarrow R(A)=R(B), \\
& A<B \Leftrightarrow R(A)<R(B),
\end{aligned}
$$

Finally, the Consistency Index $(C l)$ and a Consistency Ratio $(C R)$ are introduced to assess the consistency of the pair-wise preferences assigned in the comparison matrix.

The $C l$ and $C R$ of a comparison matrix, ' $Q$ ' are defined using the following equations (Saaty, 1990):

$$
\begin{aligned}
& C I=\frac{\left(\lambda_{\max }-n\right)}{(n-1)} \\
& C R=\frac{C l}{R I}
\end{aligned}
$$


Where, ' $n$ ' stands for the number of attributes, ' $\lambda_{\max }$ ' is the eigenvalue of the comparison matrix (Q) and ' $\mathrm{RI}$ ' is the random index which was defined by Satty and Sodenkamp (2010). A consistency ratio between 0 and 0.10 generally indicates a consistent comparison matrix (Satty and Sodenkamp, 2010).

\subsubsection{Determination of the objective weights of the attributes}

The objective weights are used for weighting the attributes based on the variation of the performance of the alternatives for each attribute. Among the available weighting methods, the entropy method has been adopted to elicit the objective weights in the decision making process for HVAC\&R systems selection. This is mainly due to the successful application of the entropy method in studies within the context of energy and built environment (Wang et al., 2008a; Wang et al., 2008c; Wang et al., 2009a).

To calculate the objective weights of the attributes, first, a decision matrix should be formed. This is a matrix with ' $m$ ' rows that represents the number of alternatives and ' $n$ ' columns representing the number of attributes as below:

$$
\begin{aligned}
& \text { Attributes } \\
& \begin{array}{lllll}
A t t_{1} & A t t_{2} & \ldots & A t t_{n}
\end{array} \\
& \text { Alternatives } \\
& G=\left[\begin{array}{cccc}
g_{1,1} & g_{1,2} & \cdots & g_{1, n} \\
g_{2,1} & g_{2,2} & \cdots & g_{2, n} \\
\cdot & \cdot & \cdots & \cdot \\
g_{m, 1} & g_{m, 2} & \cdots & g_{m, n}
\end{array}\right]_{m \times n} \quad \mid \begin{array}{c}
A L_{1} \\
A L_{2} \\
\cdot \\
A L_{m}
\end{array}
\end{aligned}
$$

In this decision matrix $(G)$, each element represents the performance of an alternative with respect to an attribute. For example, ' $g_{1,2}$ ' represents the performance of the first alternative $\left(A L_{1}\right)$ with respect to the second attribute $\left(A t t_{2}\right)$.

Because the performance of alternatives with respect to each attribute has its own dimension, the matrix $(G)$ is normalised using the following equations (Wang et al., 2008b): 


$$
\begin{aligned}
& r_{i, j}= \begin{cases}\frac{g_{i, j}}{g_{j}^{*}}, & \text { for } \mathrm{j}=1,2, \ldots, \mathrm{n}, \text { if the attribute has a characteristic of 'higher is better' } \\
\frac{g_{j}^{*}}{g_{i, j}}, & \text { for } \mathrm{j}=1,2, \ldots, \mathrm{n}, \text { if the attribute has a characteristic of 'lower is better' }\end{cases} \\
& g_{j}^{*}= \begin{cases}\max \left(g_{1, j}, g_{2, j}, \ldots, g_{m, j}\right), & \text { for } \mathrm{j}=1,2, \ldots, \mathrm{n}, \\
\min \left(g_{1, j}, g_{2, j}, \ldots, g_{m, j}\right), & \text { for } \mathrm{j}=1,2, \ldots, \mathrm{n},\end{cases} \\
& \text { if the attribute has a characteristic of 'lower is better' }
\end{aligned}
$$

The normalised decision matrix is shown as below:

Attributes

$$
\begin{array}{llll}
A t t_{1} & A t t_{2} & \ldots & A t t_{n} \\
\hline
\end{array}
$$

Alternatives

$$
R=\left[\begin{array}{cccc}
r_{1,1} & r_{1,2} & \ldots & r_{1, n} \\
r_{2,1} & r_{2,2} & \ldots & r_{2, n} \\
\cdot & \cdot & \ldots & \cdot \\
r_{m, 1} & r_{m, 2} & \ldots & r_{m, n}
\end{array}\right]_{m \times n} \quad \mid \begin{gathered}
A L_{1} \\
A L_{2} \\
\cdot \\
A L_{m}
\end{gathered}
$$

Providing the normalised decision matrix $(R)$, the entropy (en ) and objective weight $\left(W^{0}\right)$ of each attribute are calculated using the following equations (Wang et al., 2009a):

$$
\begin{aligned}
& e n_{j}=-\frac{1}{\ln (m)} \times \sum_{i=1}^{m}\left(\frac{r_{i, j}}{\sum_{i=1}^{m} r_{i, j}} \times \ln \left(\frac{r_{i, j}}{\sum_{i=1}^{m} r_{i, j}}\right)\right) \\
& W_{j}^{o}=\frac{1-e n_{j}}{\sum_{j=1}^{n}\left(1-e n_{j}\right)}, \quad \text { for } \mathrm{j}=1,2, \ldots, \mathrm{n} \text { (number of attributes) }
\end{aligned}
$$

\subsubsection{Determine the combination weights of the attributes}

As described in the previous sections, the subjective weighting method considers the preference of the decision maker on the attributes of alternatives. Whereas, the difference between the performance of various alternatives on each attribute is taken into account in the objective weights. To consider both these weights, the combination weighting methods 
integrate these two types of weights. In the open literature, the combination weighting methods have been extensively examined (Chen et al., 2008; Wang et al., 2008b; Wang et al., 2008c; Wang et al., 2009b). In general, they can be classified into two main categories; additive and multiplication weighting methods. Due to concerns about the 'multiplication effect' in the multiplication weighting methods addressed by Wang et al. (2009a), the additive combination weighting method is adopted in this study.

The simple linear combination of subjective and objective weights is shown in the following equation (Wang et al., 2008c):

$$
\begin{aligned}
& W^{c}=\sum_{k=1}^{I} \lambda_{k} W^{k}, I=2 \\
& W^{1}=W^{s}=\left(w_{1}^{s}, w_{2}^{s}, \ldots, w_{n}^{s}\right), \\
& W^{2}=W^{o}=\left(w_{1}^{o}, w_{2}^{o}, \ldots, w_{n}^{o}\right),
\end{aligned}
$$

Where, $W^{s}, W^{o}$ and $W^{c}$ respectively stand for the subjective, objective and combined weights, $\lambda_{k}$ is the linear combination coefficient and $n$ is the number of attributes.

For the determination of the linear combination coefficient $\left(\lambda_{k}\right)$, the Jaynes maximal entropy theory (Jaynes, 1957; Jaynes, 1982) and the nonlinear optimisation approach are adopted in this study. Using this approach, the following optimised linear combination coefficients are proposed to combine the subjective and objective weights (Wang et al., 2008c):

$$
\lambda_{k}=\frac{\exp \left\{-\left[1+\left(\mu \sum_{j=1}^{n} \sum_{i=1}^{m} w_{j}^{k}\left(1-r_{i, j}\right)\right) /(1-\mu)\right]\right\}}{\left.\sum_{k=1}^{l} \exp \left\{-\left[1+\left(\mu \sum_{j=1}^{n} \sum_{i=1}^{m} w_{j}^{k}\left(1-r_{i, j}\right)\right) /(1-\mu)\right)\right]\right\}}
$$

Where $\mu$, is the balance coefficient within the range between 0 and 1. ' $/$ ' represents the number of individual weights that are combined within this method, here this has a value equal to 2 because there are only subjective and objective weights are involved in this weight combination method. 


\subsection{Step 5: Rank the alternatives}

To rank the alternatives, the TOPSIS method has been adopted in this study. This method is widely used for ranking the various alternatives in a decision making process (Hwang and Yoon, 1981; Yoon and Hwang, 1995; Kahraman, 2008; Kaya and Kahraman, 2011).

Hwang and Yoon (1981) developed the Technique for Order Preference by Similarity to Ideal Solution (TOPSIS) method based on the concept that the best alternative should have the shortest distance from the positive-ideal solution and longest distance from the negativeideal solution. The positive and negative ideal solutions are respectively defined as a collection of the best and worst performance of various alternatives for each attribute (Yoon and Hwang, 1995). In a decision making problem, the positive ideal solutions $\left(A^{+}\right)$and the negative ideal solutions $\left(A^{-}\right)$are defined using the following equations (Yoon and Hwang, 1995):

$$
\begin{aligned}
& \text { Attributes } \\
& \begin{array}{llll}
A t t_{1} & A t t_{2} & \ldots & A t t_{n} \\
\hline
\end{array} \\
& Z=\left[\begin{array}{cccc}
z_{1,1}=r_{1,1} \times w_{1}^{c} & z_{1,2}=r_{1,2} \times w_{2}^{c} & \ldots & z_{1, n}=r_{1, n} \times w_{n}^{c} \\
z_{2,1}=r_{2,1} \times w_{1}^{c} & z_{2,2}=r_{2,2} \times w_{2}^{c} & \ldots & z_{2, n}=r_{2, n} \times w_{n}^{c} \\
\cdot & \cdot & \ldots & \cdot \\
z_{m, 1}=r_{m, 1} \times w_{1}^{c} & z_{m, 2}=r_{m, 2} \times w_{2}^{c} & \ldots & z_{m, n}=r_{m, n} \times w_{n}^{c}
\end{array}\right]_{m \times n} \mid \begin{array}{c}
A L_{1} \\
A L_{2} \\
\cdot \\
A L_{m}
\end{array} \\
& A^{+}=\left[z_{1}^{+}, z_{2}^{+}, \ldots, z_{n}^{+}\right] \text {, Where } z_{j}^{+}=\max \left\{z_{i, j}, \mathrm{i}=1,2, \ldots, \mathrm{m}\right\} \\
& A^{-}=\left[z_{1}^{-}, z_{2}^{-}, \ldots, z_{n}^{-}\right] \text {, Where } z_{j}^{-}=\min \left\{z_{i, j}, \mathrm{i}=1,2, \ldots, \mathrm{m}\right\}
\end{aligned}
$$

Where, ' $\mathrm{z}_{\mathrm{i}, \mathrm{j}}$ ' is an element of the weighted normalised decision matrix (Z), ' $m$ ' and ' $\mathrm{n}$ ' respectively stand for the number of alternatives and attributes, ' $\mathrm{z}_{j}{ }^{+\prime}$ and ' $\mathrm{z}_{\mathrm{j}}$ ' are the best and worst performance of alternatives with respect to the ' $\mathrm{j}^{\text {th' }}$ attribute respectively.

After defining both the positive and negative ideal solutions $\left(A^{+}\right.$and $\left.A^{-}\right)$for each alternative, the 'distance from the positive and negative ideal solutions' $\left(\mathrm{e}_{i}{ }^{+}\right.$and $\left.\mathrm{e}_{i}{ }^{-}\right)$are calculated using the following equations (Yoon and Hwang, 1995): 


$$
\begin{aligned}
& e_{i}^{+}=\sqrt{\sum_{j=1}^{n}\left(z_{i, j}-z_{j}^{+}\right)^{2}}, \text { for } \mathrm{i}=1,2, \ldots, \mathrm{m} \\
& e_{i}^{-}=\sqrt{\sum_{j=1}^{n}\left(z_{i, j}-z_{j}^{-}\right)^{2}}, \text { for } \mathrm{i}=1,2, \ldots, \mathrm{m}
\end{aligned}
$$

To integrate the effects of distance from the positive and negative ideal solutions $\left(\mathrm{e}_{\mathrm{j}}{ }^{+}\right.$and $\mathrm{e}_{\mathrm{j}}{ }^{-}$ ), for each alternative, the 'similarity to the ideal solution' $\left(A^{*}\right)$ is defined by the following equation (Yoon and Hwang, 1995):

$$
A_{i}^{*}=\frac{e_{i}^{-}}{\left(e_{i}^{-}+e_{i}^{+}\right)}, \text {for } \mathrm{i}=1,2, \ldots, \mathrm{m}
$$

This equation reveals that the ideal alternative has a 'similarity to the ideal solution' $\left(A^{*}\right)$ equal to 1 and for the anti-ideal alternative this parameter is equal to 0 . Therefore, in the TOPSIS method the alternatives are ranked based on their 'similarity to the ideal solution' $\left(A^{*}\right)$. The higher the 'similarity to the ideal solution' $\left(A^{*}\right)$, the higher the rank assigned to an alternative.

\subsection{Step 6: Perform sensitivity analysis}

In a decision making problem, some values are often subjective and judgmental. For example, the subjective weights of attributes are usually defined subjectively (Hwang and Yoon, 1981). In addition, in some cases the performances of alternatives with respect to each attribute are commonly defined subjectively (Wang et al., 2009a). Therefore, it is important to investigate the influence of these subjectivities on the final rank of the alternatives. The application of sensitivity analysis allows the question: what is it that makes a difference to this decision? (Clemen and Reilly, 2001).

In this study, the sensitivity analysis approach proposed by Mareschal (1988) is adopted to check the stability of the alternative ranks with respect to changes in the subjective weights assigned by a decision maker.

The sensitivity analysis in this study has allowed the weight of the dominant subjective attribute to be altered between $-20 \%$ and $+20 \%$ of its initial value whilst maintaining the relative weights for all of the other attributes. This allows the ranking of the alternatives to be assessed in terms of sensitivity to changes in the weight of the most influential attribute. 
In addition, the computational tool developed in this study allows the investigation the influence of changes on the weights of each attributes, not only the attribute with the highest weight, on the ranking of the alternatives.

As explained in Section 3.4, using different weighting methods such as subjective, objective and combined methods may result in different ranking (Zanakis et al., 1998; Wang et al., 2009b). Therefore, in this study a confirmatory analysis is applied to assess the consistency, reliability and therefore, relative rationality of the outcomes of the adopted weighting method. The details of this conformity analysis are provided in the appendix.

\section{The interface of the decision making tool developed in this study}

In the previous sections, 3.1 to 3.6 , the MADM steps were described and the information required for each step was described. This section introduces the proposed computational user interface of the decision making model that has been developed in this study. This computational tool and its user-friendly interface, provides a robust platform to select the most appropriate HVAC\&R systems from among a variety of alternatives through a detailed consideration of the most influential attributes of the systems. The full capability of this tool can be describing through consideration of the various parameters that are provided for the user in order to make the final decision. In addition, through the combination of these parameters an opportunity to investigate their influence on the ranking of the alternative HVAC\&R systems is provided. Consideration of the effects of climate change and the electricity decarbonisation plans in the UK into this decision making process are unique attributes of this tool. The parameters provided in the user interface of this computational decision making tool are shown in Figure 8 and the user interface of the developed tool is shown in Figure 9. 


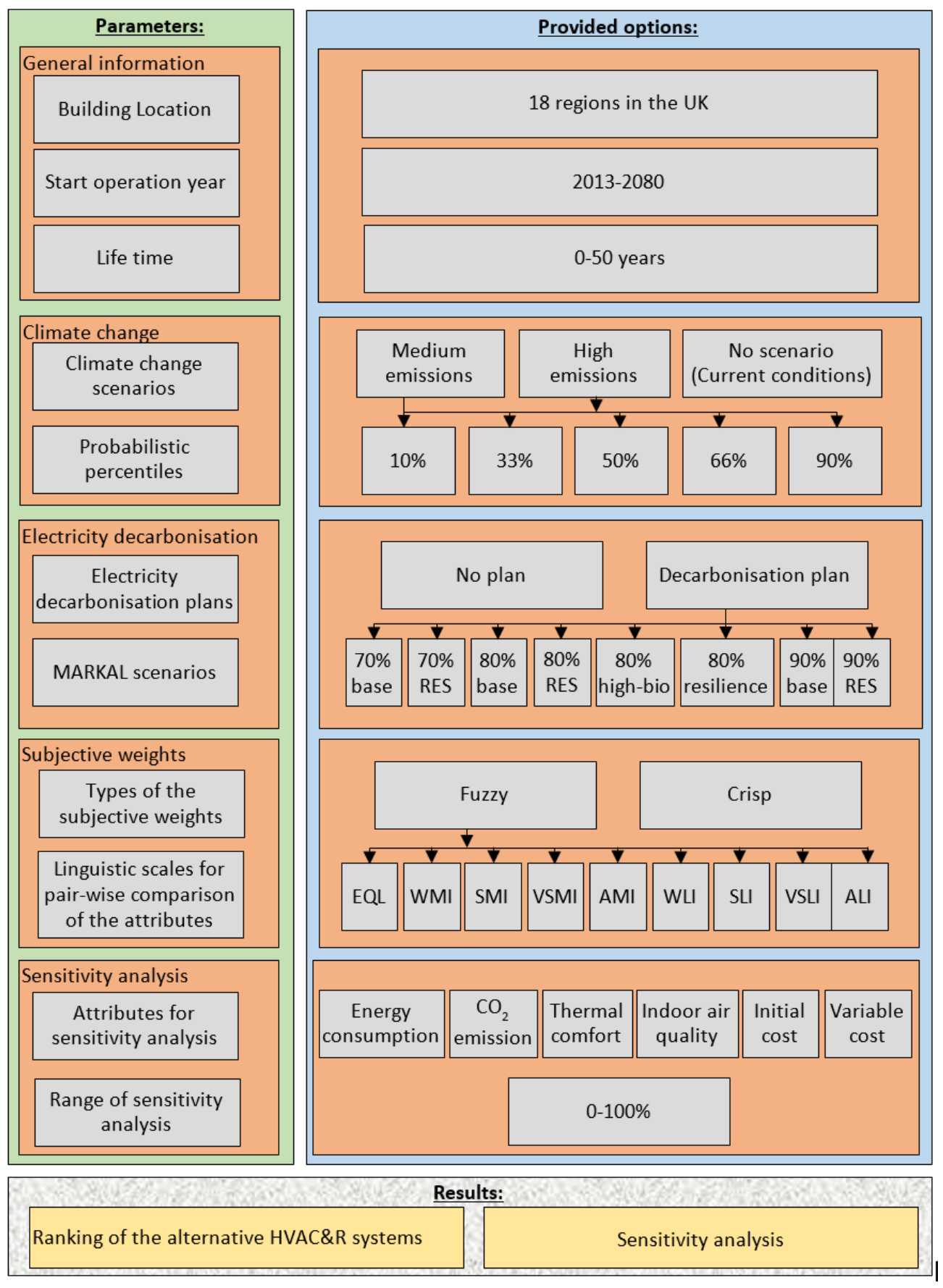

Figure 8 Parameters provided in the user interface of the developed computational tool for HVAC\&R systems selection. 


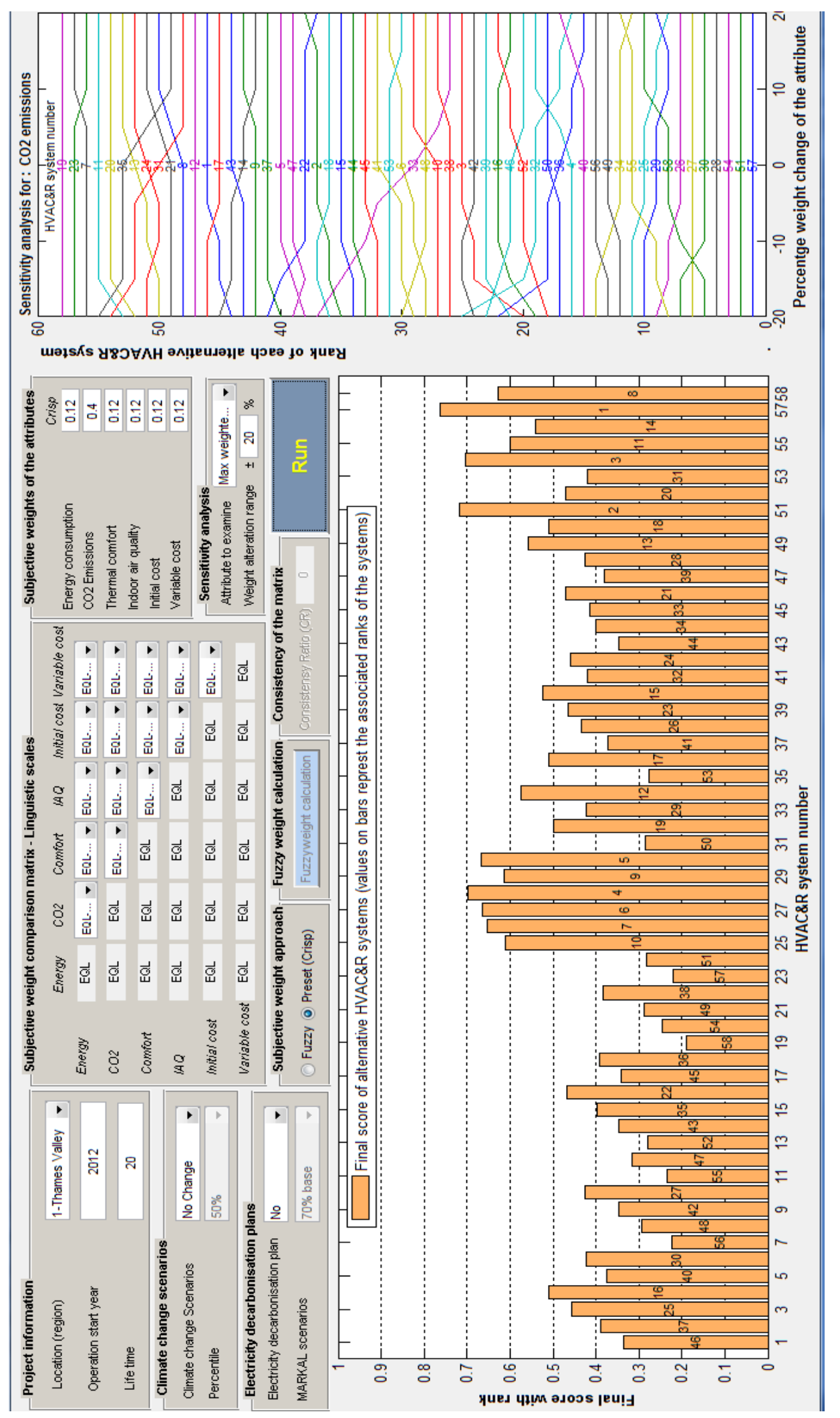

Figure 9 The user interface of the computational tool for HVAC\&R systems selection developed in this study. 


\section{Results and discussion}

The variables which can be considered in the decision making tool described in Section 4, Figure 8, allows several case scenarios to be investigated. However, a detailed explanations of all possible scenarios is not practical. Therefore, the following 14 case scenarios, Table 9, are examined in order to demonstrate the application and capability of the proposed decision making tool.

Table 9 The description of 14 case scenarios in decision making for HVAC\&R systems selection.

\begin{tabular}{|c|c|c|c|c|c|c|c|c|c|c|c|c|}
\hline \multirow[b]{2}{*}{$\begin{array}{c}\text { Case } \\
\text { No. }\end{array}$} & \multirow[b]{2}{*}{ Location } & \multirow[b]{2}{*}{$\begin{array}{l}\text { Operation } \\
\text { start year }\end{array}$} & \multirow[b]{2}{*}{$\begin{array}{l}\text { Life } \\
\text { time }\end{array}$} & \multirow[b]{2}{*}{$\begin{array}{l}\text { Climate } \\
\text { change } \\
\text { scenario }\end{array}$} & \multirow[b]{2}{*}{$\begin{array}{c}\text { Electricity } \\
\text { decarbonisation } \\
\text { plan }\end{array}$} & \multicolumn{6}{|c|}{ Subjective weights (Note 1 ) } & \multirow[b]{2}{*}{ 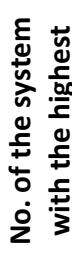 } \\
\hline & & & & & & 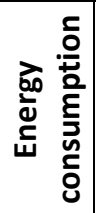 & Oิ $\frac{\stackrel{n}{\frac{o}{n}}}{\frac{\mathscr{n}}{\varepsilon}}$ & 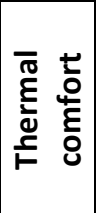 & 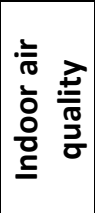 & 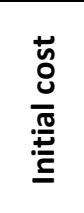 & 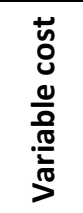 & \\
\hline 1 & $\begin{array}{c}\text { Themes } \\
\text { valley }\end{array}$ & 2013 & 25 & No & No & 0.17 & 0.17 & 0.17 & 0.17 & 0.17 & 0.17 & 55 \\
\hline 2 & $\begin{array}{c}\text { Themes } \\
\text { valley }\end{array}$ & 2013 & 25 & $\begin{array}{c}\text { High } \\
\text { emission } \\
33 \%\end{array}$ & $90 \%$ RES & 0.17 & 0.17 & 0.17 & 0.17 & 0.17 & 0.17 & 40 \\
\hline 3 & $\begin{array}{c}\text { Themes } \\
\text { valley }\end{array}$ & 2013 & 25 & No & No & 0.30 & 0.14 & 0.14 & 0.14 & 0.14 & 0.14 & 40 \\
\hline 4 & $\begin{array}{c}\text { Themes } \\
\text { valley }\end{array}$ & 2013 & 25 & $\begin{array}{c}\text { High } \\
\text { emission } \\
66 \%\end{array}$ & 80\% Resilience & 0.30 & 0.14 & 0.14 & 0.14 & 0.14 & 0.14 & 40 \\
\hline 5 & $\begin{array}{c}\text { Themes } \\
\text { valley }\end{array}$ & 2013 & 25 & No & No & 0.11 & 0.45 & 0.11 & 0.11 & 0.11 & 0.11 & 57 \\
\hline 6 & $\begin{array}{c}\text { Themes } \\
\text { valley }\end{array}$ & 2013 & 25 & $\begin{array}{c}\text { Medium } \\
\text { emission } \\
66 \%\end{array}$ & $80 \%$ High bio & 0.11 & 0.45 & 0.11 & 0.11 & 0.11 & 0.11 & 40 \\
\hline 7 & $\begin{array}{c}\text { Themes } \\
\text { valley }\end{array}$ & 2013 & 25 & No & No & 0.10 & 0.10 & 0.30 & 0.30 & 0.10 & 0.10 & 55 \\
\hline 8 & $\begin{array}{c}\text { Themes } \\
\text { valley }\end{array}$ & 2013 & 25 & $\begin{array}{c}\text { Medium } \\
\text { emission } \\
33 \% \\
\end{array}$ & $90 \%$ RES & 0.10 & 0.10 & 0.30 & 0.30 & 0.10 & 0.10 & 41 \\
\hline 9 & $\begin{array}{c}\text { Themes } \\
\text { valley }\end{array}$ & 2013 & 25 & No & No & 0.13 & 0.13 & 0.13 & 0.13 & 0.13 & 0.35 & 57 \\
\hline 10 & $\begin{array}{c}\text { Themes } \\
\text { valley }\end{array}$ & 2013 & 25 & $\begin{array}{c}\text { Medium } \\
\text { emission } \\
50 \%\end{array}$ & $90 \%$ RES & 0.13 & 0.13 & 0.13 & 0.13 & 0.13 & 0.35 & 40 \\
\hline 11 & $\begin{array}{c}\text { Themes } \\
\text { valley }\end{array}$ & 2013 & 25 & No & No & 0.12 & 0.12 & 0.12 & 0.12 & 0.40 & 0.12 & 55 \\
\hline 12 & $\begin{array}{c}\text { Themes } \\
\text { valley }\end{array}$ & 2013 & 10 & No & No & 0.12 & 0.12 & 0.12 & 0.12 & 0.40 & 0.12 & 58 \\
\hline 13 & $\begin{array}{c}\text { Themes } \\
\text { valley }\end{array}$ & 2013 & 25 & $\begin{array}{c}\text { High } \\
\text { emission } \\
66 \%\end{array}$ & No & 0.13 & 0.35 & 0.13 & 0.13 & 0.13 & 0.13 & 55 \\
\hline
\end{tabular}




\begin{tabular}{|c|c|c|c|c|c|c|c|c|c|c|c|c|}
\hline \multirow[b]{2}{*}{$\begin{array}{l}\text { Case } \\
\text { No. }\end{array}$} & \multirow[b]{2}{*}{ Location } & \multirow[b]{2}{*}{$\begin{array}{l}\text { Operation } \\
\text { start year }\end{array}$} & \multirow[b]{2}{*}{$\begin{array}{l}\text { Life } \\
\text { time }\end{array}$} & \multirow[b]{2}{*}{$\begin{array}{l}\text { Climate } \\
\text { change } \\
\text { scenario }\end{array}$} & \multirow[b]{2}{*}{$\begin{array}{c}\text { Electricity } \\
\text { decarbonisation } \\
\text { plan }\end{array}$} & \multicolumn{6}{|c|}{ Subjective weights (Note 1 ) } & \multirow{2}{*}{ 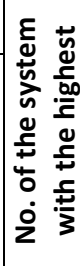 } \\
\hline & & & & & & 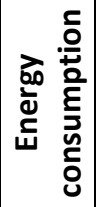 & 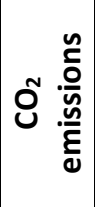 & 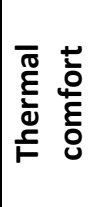 & 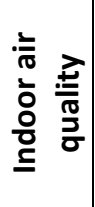 & $\frac{\breve{n}}{0}$ & 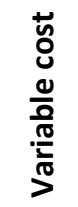 & \\
\hline 14 & $\begin{array}{l}\text { North- } \\
\text { west } \\
\text { Scotland }\end{array}$ & 2013 & 25 & $\begin{array}{c}\text { High } \\
\text { emission } \\
66 \%\end{array}$ & No & 0.13 & 0.35 & 0.13 & 0.13 & 0.13 & 0.13 & 57 \\
\hline
\end{tabular}

Notes:

1. The subjective weights are the outcomes of the fuzzy linguistic pair-wise comparison of attributes.

2. System numbers are defined in Table 4.

3. Electricity decarbonisation plans are based on the MARKAL scenarios provided in Figure 5 and Table 7.

4. Climate change scenarios addressed in Section 3.2.1 according to (Murphy et al., 2009). Table 6 shows the highest and lowest changes in mean daily temperature, mean daily maximum temperature and mean daily minimum temperature in winter and summer by the 2080s, relative to $1961-1990$.

5. Degradation of the energy performance of systems is not considered in this study.

In addition, as shown in the user interface, Figure 9, the rank order of the alternative HVAC\&R systems introduced in Table 4 and sensitivity analysis will be examined. Figure 10 shows the outputs of the decision making tool for the fourth case study scenario introduced in Table 9.

In the first case scenario, Table 9, for a reference building located in London, Thames Valley, both the climate change scenarios and the electricity decarbonisation plans are ignored and all the attributes are assumed to have an equal preference or subjective weight. In this case, the results shown in Table 10 reveals that the gas boiler with vapour compression air cooled chiller linked to fan coil units, HVAC\&R system number 55 in Table 4, has the highest rank and the lowest rank belongs to the HVAC\&R system number 31 which is a CCHP system linked to a CAV air distribution system with reheat. HVAC\&R system number 55 is the most common HVAC\& system for "standard air conditioned buildings" in the UK (ECG-19, 2000; CIBSE, 2012) , which has been selected as the most appropriate system under this scenario. This is mainly due to considering equal preferences between all attributes and ignoring the influence of climate change and any electricity decarbonisation plan in the future.

In the second case scenario, Table 9, the electricity decarbonisation according to ' $90 \%$ RES' plan and the climate change scenario complied with '33\% high emissions' are added to the first case scenario. The outcome of the decision making process under this case scenario, 
Table 10, shows that by considering these two parameters, the first highly ranked alternative becomes the ground coupled heat pump (GCHP) system linked to a VAV air distribution with heat recovery, the alternative HVAC\&R system number 40 in Table 4. Comparing this scenario with the first scenario shows that considering a high emission climate change scenario encourages deployment of more energy efficient technologies; for example GCHP systems. In addition, by moving towards decarbonisation of electricity it would be more appropriate to select the heating systems that run with electricity and produce lower energy related $\mathrm{CO}_{2}$ emissions than those use natural gas; for example gas boilers.

In the third case scenario, Table 9, the weights of the attributes in the first case scenario are changed and the preference of energy consumption is assumed more than twice the weights of the other attributes. The result of the decision making process, Table 10, demonstrates that the ground coupled heat pump (GCHP) system linked to a VAV air distribution with heat recovery, HVAC\&R system number 40 in Table 4, is the first choice, the same as for the second case scenario. The lowest rank is for the CCHP system linked to a CAV air distribution system with reheat, HVAC\&R system number 31. Comparing this scenario with scenario 1 shows that due to increasing the weight/importance of energy as an attribute for decision making the GCHP and VAV systems are selected as the most appropriate alternatives compared to gas boiler in Scenario 1. This is mainly due to the fact that heat pump technology is more energy efficient than gas boiler (ASHRAE, 2016). Because of this unique attribute, under this scenario, the first 12 highly ranked proposed alternatives, Table 10, are heat pump systems.

In the fourth case scenario, Table 9, the electricity decarbonisation according to ' $80 \%$ Resilience' plan and the climate change scenario complied with '66\% high emissions' are added to the third case scenario. The results of decision making under this case scenario, Figure 10a, again show that, the GCHP system linked to a VAV air distribution with heat recovery, HVAC\&R system number 40 in Table 4, has the highest rank among the alternatives. This system is selected as the most appropriate alternative because of considering the weight of energy consumption more than twice the weight of other attributes together with taking into account the influence of climate change and also the electricity decarbonisation plan. In addition, as it is shown in Figure 10b, the order of the first six highly ranked alternatives is not sensitive to any alternation of the energy consumption weight $\pm 20 \%$ of its initial value. 
In the fifth case scenario, Table 9, the weights of attributes in the first case scenario are changed and the preference of $\mathrm{CO}_{2}$ emissions is assumed almost four times greater than the preference of other attributes. In this case, the result of decision making provided in Table 10 reveals that the CCHP system linked to fan coil units, HVAC\&R system number 57 in Table 4, is the first choice and the lowest rank belongs to the absorption chiller with gas boiler linked to a CAV air distribution system with reheat, which is the HVAC\&R system number 19 . In this scenario the CCHP system linked to fan coil units is selected as the most appropriate alternative mainly due to: 1 - the weight associated with initial cost is about four times lower than the preference of $\mathrm{CO}_{2}$ emission, which makes the high initial cost associated with CCHP technology more acceptable, 2- Considering the current high carbon intensity of the electricity from national grid, the CCHP systems are able to provide electricity with lower carbon intensity compared with power plants by the appropriate use of the produced heat in the process (CIBSE-AM12, 2013).

In the sixth case scenario, Table 9, the electricity decarbonisation according to ' $80 \%$ High bio' plan and the climate change scenario complied with ' $66 \%$ medium emissions' are added to the fifth case scenario. For this scenario the highest rank is for the GCHP system linked to a VAV air distribution with heat recovery, HVAC\&R system number 40 in Table 4. In other words, comparison of this case scenario with the previous one shows that, consideration of the climate change and electricity decarbonisation plan shifts the highly ranked alternatives from CCHP systems to GCHP systems. This is mainly due to the fact that the preference of $\mathrm{CO}_{2}$ emissions is assumed almost four times greater than the preference of other attributes together with consideration of the electricity decarbonisation plan in the future, which makes the CCHP less attractive compared to GCHP.

In the seventh case scenario, Table 9, the weights of attributes in the first case scenario are changed and the preference of thermal comfort and indoor air quality are assumed three times greater than the preference of other attributes. As mentioned in Table 10, for this case scenario the gas boiler with vapour compression air cooled chiller linked to fan coil units, HVAC\&R system number 55 in Table 4, is the first highly ranked alternative. This is mainly due to the capability of the fan coil system in providing local control on the indoor environmental conditions for each individual thermal zones in buildings (ASHRAE, 2016). In addition, 
considering a lower preference for energy consumption and energy related $\mathrm{CO}_{2}$ emissions compared to thermal comfort and indoor air quality discourages the selection of high energy efficient systems like CCHP systems (CIBSE-AM12, 2013; ASHRAE, 2016).

In the eighth case scenario, Table 9, the electricity decarbonisation according to ' $90 \%$ RES' plan and the climate change scenario complied with '33\% medium emissions' are added to the seventh case scenario. The result of this case scenario provided in Table 10 reveals that, the GCHP system linked to a CAV air distribution with economiser, HVAC\&R system number 41 in Table 4, has the highest rank among the alternatives. Increasing the energy demand due to climate change and considering the electricity decarbonisation plan in one hand and low preference on initial cost on the other hand made the high energy efficient systems such as alternative number 41 more attractive than other alternatives.

In the ninth case scenario, Table 9, the weights of attributes in the first case scenario are changed and the preference of variable cost is assumed around three times greater than the preference of other attributes. Under such circumstances mentioned in Table 10, the CCHP system linked to fan coil units, HVAC\&R system number 57 in Table 4, is the first choice. This is mainly due to the nature of CHP on simultaneously providing heat and power, which results in low cost generation of electricity (CIBSE-AM12, 2013). In addition, in this case, the lowest rank belongs to the absorption chiller with gas boiler linked to a CAV air distribution system with reheat.

In the tenth case scenario, Table 9, the electricity decarbonisation according to '90\% RES' plan and the climate change scenario complied with ' $50 \%$ medium emissions' are added to the ninth case scenario. The results of this case scenario shown in Table 10 reveals that, the GCHP system linked to a VAV air distribution with heat recovery, HVAC\&R system number 40 in Table 4, has the highest rank among the alternatives. This is mainly because of increasing the building energy demand under the considered climate change scenario and also consideration of the electricity decarbonisation plan in the future which makes the GCHP systems more efficient in terms of energy consumption and energy related $\mathrm{CO}_{2}$ emission compared to $\mathrm{CCHP}$ which was the first priority under case scenario number 9. 
In the eleventh case scenario, Table 9, the weights of attributes in the first case scenario are changed and the preference of initial cost is assumed more than three times of the preference of other attributes. According to the results presented in Table 10, the gas boiler with vapour compression air cooled chiller linked to fan coil units, HVAC\&R system number 55 in Table 4, is the first choice. In addition, in this case, the lowest rank belongs to the CCHP system linked to a CAV air distribution system with reheat and economiser, HVAC\&R system number 35. This is mainly due to the fact that initial cost associated with CCHP system is very high compared to the rest of alternatives (CIBSE, 2008; Abramson et al., 2005 and Davis Langdon, 2016).

In the twelfth case scenario, Table 9, to consider the influence of life time of the systems, the life time of the previous case is reduced to 10 years. The outcomes of the decision making provided in Table 10 suggest that the local split air source heat pump unit, HVAC\&R system number 58 in Table 4, has the highest rank among the alternatives. This is mainly due to the lower initial cost together with shorter expected life time for local split air source heat pump unit compared with central systems (CIBSE, 2008; Abramson et al., 2005.)

In the thirteenth case scenario, Table 9, the weights of attributes in the first case scenario are changed and the preference of $\mathrm{CO}_{2}$ emissions is assumed just less than three times of the preference of other attributes. Also, the climate change scenario complied with ' $66 \%$ high emissions' is added to the first case scenario. For this case, Table 10, suggests the gas boiler with vapour compression air cooled chiller linked to fan coil units, HVAC\&R system number 55 in Table 4, as the first choice. In addition, in this case, the absorption chiller with gas boiler linked to a CAV air distribution system with reheat, HVAC\&R system number 19, has the lowest rank among alternatives. This is mainly due to the fact that the energy performance of absorption chillers are very low compared to heat pump systems (ASHRAE, 2016). Under such a scenario with high priority for $\mathrm{CO}_{2}$ emissions, this would have a very negative impact on the ranking of the HVAC\&R system number 19.

Finally, the fourteenth case scenario, Table 9, investigates the influence of building location on HVAC\&R systems selection. In this case, the location of the case scenario mentioned in the previous case is changed from Thames Valley to Northwest Scotland. The result of decision 
making provided in Table 10 shows that the CCHP system linked to fan coil units, HVAC\&R system number 57 in Table 4, is the first choice; whereas with the same parameters in London, case scenario No 13, the best alternative was the gas boiler with vapour compression air cooled chiller linked to fan coil units, HVAC\&R system number 55 . This is mainly due to the colder weather conditions in the North that results in longer period of operation for the CHP unit which makes utilisation of this unit more justifiable. 


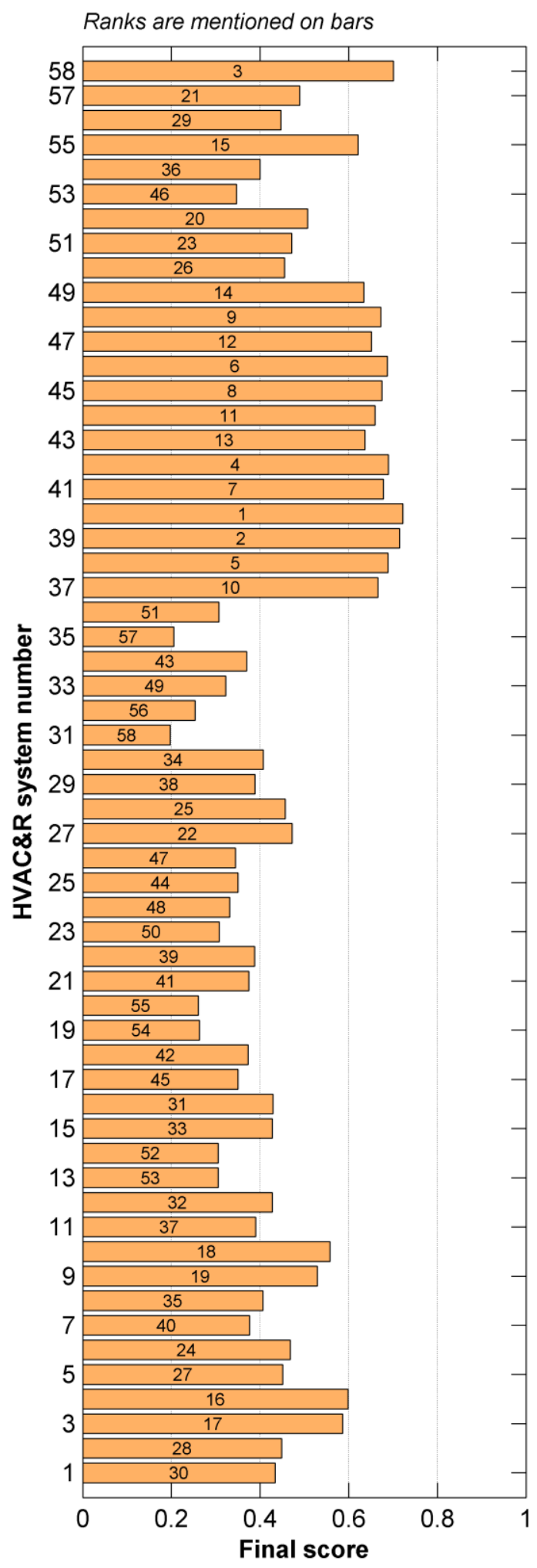

a)

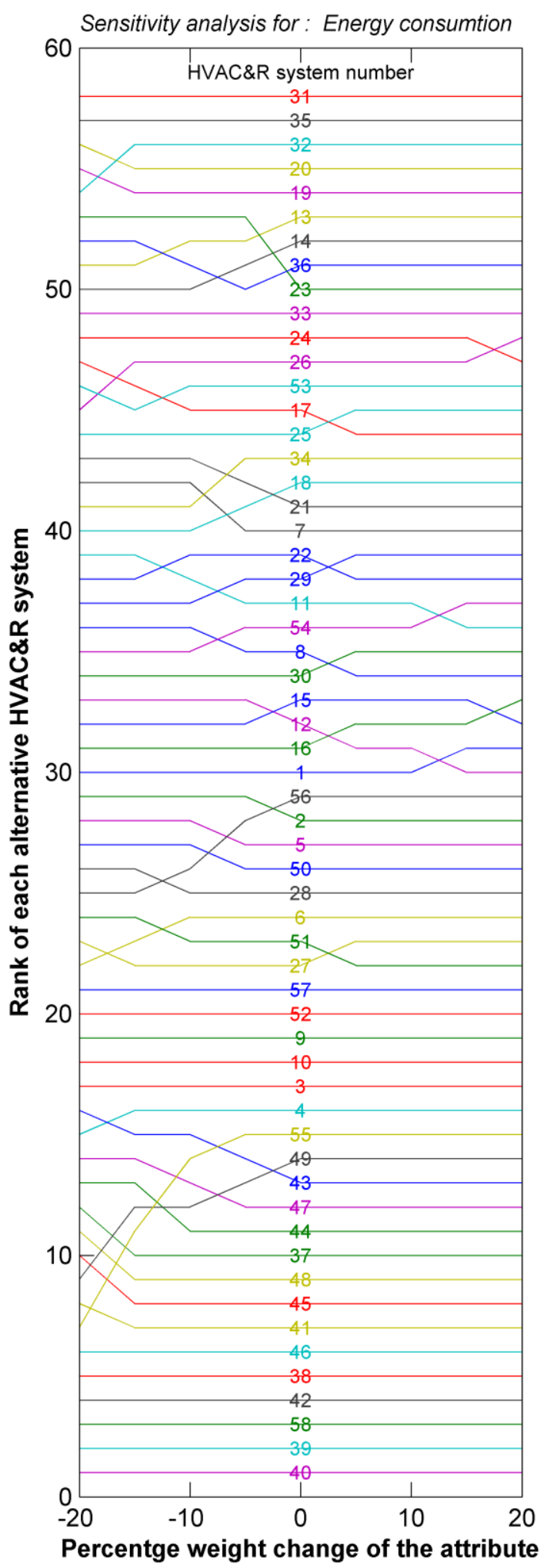

b)

Figure 10 Alternative HVAC\&R systems a) final ranks and b) sensitivity analysis for the case scenario number 4. 
Table 10 Ranks of the alternative HVAC\&R systems under different case study scenarios.

\begin{tabular}{|c|c|c|c|c|c|c|c|c|c|c|c|c|c|c|}
\hline \multirow{2}{*}{$\begin{array}{l}\text { Ranks of } \\
\text { the the } \\
\text { alternative } \\
\text { HVAC\&R } \\
\text { systems }\end{array}$} & \multicolumn{14}{|c|}{ Alternative HVAC\&R systems studied under different case scenarios (Notes 1 and 2) } \\
\hline & 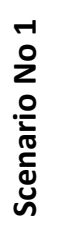 & 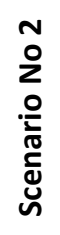 & 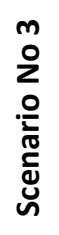 & 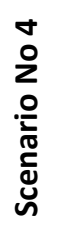 & 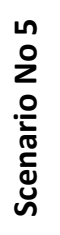 & 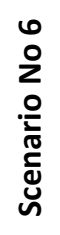 & 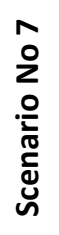 & 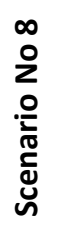 & 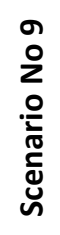 & 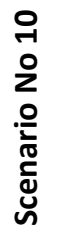 & 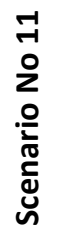 & 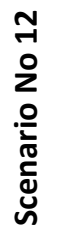 & 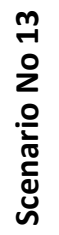 & 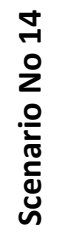 \\
\hline 1 & 55 & 40 & 40 & 40 & 57 & 40 & 55 & 41 & 57 & 40 & 55 & 58 & 55 & 57 \\
\hline 2 & 49 & 39 & 39 & 39 & 55 & 58 & 49 & 39 & 55 & 57 & 3 & 55 & 57 & 55 \\
\hline 3 & 40 & 55 & 58 & 58 & 51 & 39 & 57 & 40 & 40 & 55 & 58 & 3 & 49 & 58 \\
\hline 4 & 4 & 38 & 42 & 42 & 58 & 46 & 40 & 55 & 51 & 39 & 4 & 4 & 58 & 51 \\
\hline 5 & 57 & 42 & 46 & 38 & 28 & 42 & 39 & 47 & 28 & 46 & 1 & 1 & 40 & 49 \\
\hline 6 & 39 & 58 & 38 & 46 & 49 & 38 & 56 & 42 & 49 & 49 & 56 & 2 & 51 & 28 \\
\hline 7 & 58 & 41 & 41 & 41 & 54 & 48 & 41 & 49 & 54 & 42 & 2 & 5 & 28 & 40 \\
\hline 8 & 3 & 46 & 48 & 45 & 40 & 45 & 4 & 48 & 39 & 51 & 5 & 56 & 4 & 56 \\
\hline 9 & 56 & 49 & 45 & 48 & 27 & 41 & 3 & 45 & 27 & 28 & 9 & 9 & 27 & 54 \\
\hline 10 & 42 & 45 & 44 & 37 & 56 & 44 & 42 & 46 & 56 & 38 & 6 & 6 & 54 & 27 \\
\hline 11 & 46 & 48 & 37 & 44 & 30 & 37 & 47 & 37 & 46 & 48 & 10 & 10 & 56 & 50 \\
\hline 12 & 38 & 37 & 47 & 47 & 4 & 47 & 51 & 38 & 42 & 27 & 15 & 15 & 39 & 4 \\
\hline 13 & 41 & 47 & 49 & 43 & 34 & 43 & 50 & 3 & 30 & 4 & 52 & 49 & 30 & 39 \\
\hline 14 & 48 & 44 & 43 & 49 & 50 & 49 & 46 & 43 & 4 & 45 & 49 & 52 & 3 & 30 \\
\hline 15 & 45 & 4 & 55 & 55 & 26 & 55 & 48 & 4 & 38 & 54 & 12 & 12 & 46 & 46 \\
\hline 16 & 51 & 3 & 4 & 4 & 46 & 4 & 52 & 44 & 50 & 41 & 16 & 8 & 42 & 42 \\
\hline 17 & 50 & 43 & 3 & 3 & 39 & 3 & 27 & 58 & 26 & 44 & 8 & 11 & 52 & 34 \\
\hline 18 & 28 & 10 & 57 & 10 & 42 & 10 & 45 & 57 & 34 & 30 & 13 & 16 & 34 & 26 \\
\hline 19 & 52 & 9 & 10 & 9 & 29 & 9 & 28 & 10 & 48 & 56 & 17 & 17 & 50 & 29 \\
\hline 20 & 27 & 52 & 51 & 52 & 3 & 57 & 38 & 52 & 41 & 37 & 11 & 13 & 26 & 16 \\
\hline 21 & 10 & 57 & 50 & 57 & 52 & 51 & 54 & 9 & 45 & 47 & 7 & 7 & 38 & 38 \\
\hline 22 & 37 & 56 & 28 & 27 & 16 & 52 & 29 & 56 & 25 & 3 & 14 & 14 & 10 & 3 \\
\hline 23 & 47 & 6 & 27 & 51 & 25 & 27 & 37 & 5 & 44 & 34 & 18 & 21 & 48 & 48 \\
\hline 24 & 44 & 50 & 9 & 6 & 38 & 28 & 5 & 50 & 52 & 50 & 21 & 18 & 45 & 52 \\
\hline 25 & 16 & 5 & 52 & 28 & 48 & 50 & 10 & 51 & 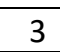 & 26 & 23 & 23 & 29 & 41 \\
\hline 26 & 54 & 51 & 56 & 50 & 36 & 6 & 58 & 27 & 16 & 52 & 22 & 22 & 41 & 45 \\
\hline 27 & 6 & 27 & 16 & 5 & 41 & 56 & 6 & 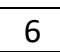 & 25 & 29 & 53 & 19 & 25 & 25 \\
\hline 28 & 43 & 2 & 15 & 2 & 45 & 5 & 30 & 15 & 47 & 43 & 19 & 24 & 16 & 10 \\
\hline 29 & 30 & 28 & 6 & 56 & 10 & 2 & 16 & 29 & 37 & 10 & 24 & 53 & 6 & 44 \\
\hline 30 & 15 & 16 & 54 & 1 & 44 & 30 & 15 & 17 & 36 & 25 & 50 & 50 & 44 & 15 \\
\hline 31 & 9 & 15 & 30 & 16 & 33 & 1 & 44 & 28 & 10 & 16 & 20 & 20 & 36 & 47 \\
\hline 3 & 2 & 4 & 2 & 1 & 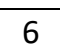 & 1 & 43 & 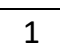 & 6 & 6 & 37 & 37 & 37 & 36 \\
\hline 3 & 5 & 12 & 5 & 15 & 32 & 54 & 9 & 16 & 43 & 36 & 39 & 39 & 2 & 53 \\
\hline 3 & 29 & 54 & 25 & 30 & 53 & 1 & 17 & 1 & 53 & 33 & 57 & 41 & 47 & 37 \\
\hline 3 & 26 & 30 & 22 & 8 & - & 34 & 2 & 12 & 32 & 15 & 41 & 38 & 33 & 6 \\
\hline 36 & 34 & 8 & 34 & 54 & 47 & 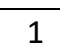 & 53 & 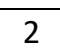 & 15 & 2 & 8 & 57 & 15 & 33 \\
\hline 37 & 1 & 22 & 1 & 11 & 37 & 29 & 34 & 54 & 33 & 58 & 40 & 40 & 5 & 32 \\
\hline 38 & 25 & 11 & 12 & 29 & 2 & 8 & 1 & 30 & 2 & 32 & 47 & 47 & 53 & 22 \\
\hline 39 & 53 & 18 & 21 & 22 & 18 & 22 & 2 & 18 & 18 & 53 & 43 & 43 & 9 & 18 \\
\hline 40 & 18 & 29 & 26 & 7 & 22 & 33 & 18 & 21 & 58 & 5 & 25 & 45 & 32 & 43 \\
\hline 41 & 22 & 21 & 18 & 21 & 5 & 11 & 26 & 23 & 5 & 9 & 45 & 42 & 43 & 2 \\
\hline 42 & 17 & 17 & 53 & 18 & 43 & 21 & 12 & 53 & 22 & 18 & 27 & 25 & 18 & 5 \\
\hline 43 & 12 & 7 & - & 34 & 9 & 18 & 22 & 22 & 9 & 22 & 42 & 27 & 1 & 9 \\
\hline 44 & 36 & 34 & 25 & 25 & 17 & 7 & 36 & 25 & 1 & 1 & 48 & 44 & 22 & 17 \\
\hline
\end{tabular}




\begin{tabular}{|c|c|c|c|c|c|c|c|c|c|c|c|c|c|c|}
\hline \multirow{2}{*}{$\begin{array}{l}\text { Ranks of } \\
\text { the the } \\
\text { alternative } \\
\text { HVAC\&R } \\
\text { systems }\end{array}$} & \multicolumn{14}{|c|}{ Alternative HVAC\&R systems studied under different case scenarios (Notes 1 and 2) } \\
\hline & 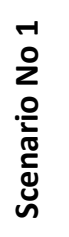 & $\begin{array}{l}N \\
0 \\
2 \\
.0 \\
\frac{0}{2} \\
\frac{0}{0} \\
\stackrel{d}{n}\end{array}$ & $\begin{array}{l}m \\
0 \\
2 \\
o \\
\cdot \frac{0}{2} \\
\frac{\pi}{0} \\
\stackrel{d}{N}\end{array}$ & 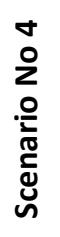 & 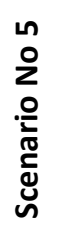 & $\begin{array}{l}0 \\
0 \\
2 \\
.0 \\
\frac{0}{2} \\
\frac{0}{d} \\
\text { U }\end{array}$ & 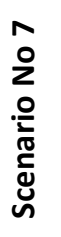 & 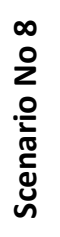 & 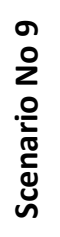 & 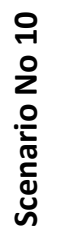 & 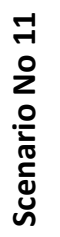 & 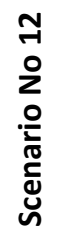 & 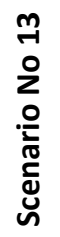 & 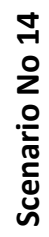 \\
\hline 45 & 14 & 53 & 17 & 17 & 1 & 25 & 11 & 7 & 17 & 12 & 44 & 48 & 12 & 14 \\
\hline 46 & 8 & 25 & 11 & 53 & 14 & 26 & 33 & 8 & 14 & 17 & 46 & 46 & 17 & 1 \\
\hline 47 & 21 & 26 & 7 & 26 & 12 & 53 & 21 & 34 & 12 & 14 & 28 & 28 & 8 & 21 \\
\hline 48 & 33 & 13 & 33 & 24 & 35 & 36 & 23 & 24 & 35 & 8 & 29 & 29 & 14 & 12 \\
\hline 49 & 13 & 14 & 36 & 33 & 21 & 17 & 13 & 33 & 21 & 21 & 26 & 26 & 21 & 13 \\
\hline 50 & 11 & 24 & 24 & 23 & 31 & 24 & 24 & 13 & 31 & 31 & 30 & 30 & 31 & 8 \\
\hline 51 & 32 & 23 & 14 & 36 & 8 & 14 & 14 & 36 & 8 & 35 & 51 & 51 & 13 & 35 \\
\hline 52 & 24 & 33 & 23 & 14 & 24 & 23 & 8 & 26 & 13 & 13 & 54 & 54 & 24 & 24 \\
\hline 53 & 7 & 36 & 13 & 13 & 13 & 13 & 35 & 35 & 24 & 24 & 34 & 34 & 35 & 31 \\
\hline 54 & 23 & 19 & 32 & 19 & 11 & 32 & 32 & 14 & 11 & 11 & 33 & 33 & 11 & 11 \\
\hline 55 & 20 & 20 & 20 & 20 & 20 & 19 & 7 & 19 & 20 & 7 & 36 & 36 & 7 & 20 \\
\hline 56 & 19 & 32 & 19 & 32 & 7 & 20 & 31 & 20 & 7 & 20 & 31 & 31 & 20 & 23 \\
\hline 57 & 35 & 35 & 35 & 35 & 23 & 35 & 19 & 32 & 23 & 23 & 32 & 32 & 23 & 7 \\
\hline 58 & 31 & 31 & 31 & 31 & 19 & 31 & 20 & 31 & 19 & 19 & 35 & 35 & 19 & 19 \\
\hline \multicolumn{15}{|l|}{ Notes: } \\
\hline
\end{tabular}

\section{Conclusion}

The aim of the study described in this paper was to investigate a range of decision making methods and develop a robust computational decision making tool to select and rank the alternative HVAC\&R systems. This paper reviewed and classified a broad range of principal multiple attribute decision making methods. Among them, the fuzzy multiple attribute decision making approach was adopted. This was mainly due to the ability of this method to deal with the uncertainties and imprecisions of the linguistic terms involved in the decision making process. In order to make a decision on HVAC\&R systems selection, 58 alternative HVAC\&R systems, including both primary and secondary parts, were examined. Then, six attributes of these alternative systems including; energy consumption, $\mathrm{CO}_{2}$ emissions, thermal comfort, indoor air quality, initial cost and variable costs, were taken into account in the decision making process.

Through examination of alternative HVAC\&R systems, an evaluation of the attributes for each alternative and by developing a fuzzy decision making model, a computation fuzzy multiple attribute decision making tool was developed. This computational tool provides a platform to perform decision making for HVAC\&R systems selection by taking into the account the 
subjective preference of attributes associated with alternative systems as well as the following key parameters:

- Climate change scenarios, of low and high emissions each with the 5 probability percentiles of , $10 \%, 33 \%, 50 \%, 66 \%$ and $90 \%$,

- Electricity decarbonisation plans provided in the MARKAL model,

- Location of the building, in all 18 regions in the UK.

The reliability, robustness, capability and user-friendly structure of the developed tool were demonstrated by an investigation into 14 case scenarios. In addition, both sensitivity and confirmatory analysis were conducted to examine the sensitivity of the results to the subjective weights and weighting methods respectively. The results of this study show that:

- The subjective preferences of the attributes associated with alternative HVAC\&R systems significantly influence the ranking of the alternatives,

- Climate change scenarios, electricity decarbonisation plans and the location of the building are influential parameters for HVAC\&R systems selection,

- When the UK future probabilistic climate change scenarios and the UK government electricity decarbonisation plans are considered across 58 alternative HVAC\&R systems, the ground coupled heat pump (GCHP) system is highly likely to be the most appropriate primary HVAC\&R system.

\section{Acknowledgements:}

The authors would like to acknowledge the supports received from the School of the Built Environment, at the University of Reading. 


\section{References}

Abramson, B., Herman, D. and Lung, S.W., 2005. Interactive web-based owning and operating cost database, ASHRAE research project 1237. Atlanta: American Society of Heating Refrigerating and Air-conditioning Engineers.

ASHRAE., 2016. ASHRAE handbook-HVAC systems and equipment. Atlanta: American Society of Heating, Refrigeration and Air-conditioning Engineers.

ASHRAE, 2015. ASHRAE handbook-HVAC Applications. American Society of Heating, Refrigerating and Air-Conditioning Engineers, Atlanta.

Atkin, B., Brooks, A., 2009. Total facilities management. Wiley-Blackwell, Oxford.

Avgelis, A., Papadopoulos, A. M., 2009. Application of multi-criteria analysis in designing HVAC systems. Energy and Buildings. 41(7), 774-780.

Baker, D., Bridges, D., Hunter, R., Johnson, G., Krupa, J., Murphy, J., Sorenson, K., 2001. Guidebook to decision-making methods. USA Department of Energy.

BenSalah, C., Chaabene, M., BenAmmar, M., 2008. Multi-criteria fuzzy algorithm for energy management of a domestic photovoltaic panel. Renewable Energy. 33(5), 993-1001.

Bhowmik, M., Pal, M., Pal, A., 2008. Circulant triangular fuzzy number matrices. Journal of Physical Sciences. 12, 141-154.

Bouyssou, D., 1986. Some remarks on the notion of compensation in MCDM. European Journal of Operational Research. 26(1), 150-160.

Brigges, R. S., Crawley, D. B., Schliesing, J. S., 1992. Energy requirements of office buildings, vol-1. Pacific Northwest Laboratory for Gas Research Institute, Battelle.

BS/ISO:7730 (2005). Ergonomics of the thermal environment. Analytical determination and interpretation of thermal comfort using calculation of the PMV and PPD indices and local thermal comfort criteria. London: British/European Standard.

Buckley, J. J., Feuring, T., Hayashi, Y., 2001. Fuzzy hierarchical analysis revisited. European Journal of Operational Research. 129(1), 48-64.

Chatzimouratidis, A. I., Pilavachi, P. A., 2007. Objective and subjective evaluation of power plants and their non-radioactive emissions using the analytic hierarchy process. Energy Policy. 35(8), 4027-4038.

Chen, S. H., Hsieh, C. H., 2000. Representation, ranking, distance, and similarity of L-R type fuzzy number and application. Australian Journal of Intelligent Processing Systems. 6(4), 217-229. 
Chen, Y. H., Niu, D. X., Gu, Z. H., Zhang, Y. Y. (2008) International Conference on Risk Management \& Engineering Management, ICRMEM '08. Beijing.

CIBSE 2008., Maintenance engineering and management - Guide M. London: Chartered Institution of Building Services Engineers.

CIBSE, 2009. Building control systems - Guide H. 2nd edn. Chartered Institution of Building Services Engineers, London.

CIBSE-TM41, 2006. Degree-days theory and application. Chartered Institution of Building Services Engineers, London.

CIBSE-AM12, 2013. Combined heat and power for buildings. 2nd ed. London: Chartered Institution of Building Services Engineers.

CIBSE, 2012. Energy efficiency in buildings - Guide F. 2nd edn. Chartered Institution of Building Services Engineers, London.

Clemen, R. T., Reilly, T., 2001. Making hard decisions with DecisionTools. Duxbury Press, California.

CT, 2007. Degree days for energy management-a practical introduction. Carbon Trust, London.

Davis Langdon, L.L.P. 2016., Spon's mechanical and electrical services price book. London: Taylor \& Francis.

Dawes, R. M., Corrigan, B., 1974. Linear models in decision making. Psychological Bulletin. 81(2), 95-106.

DCLG, 2007. Report on carbon reductions in new non-domestic buildings. 2nd edn. Department for Communities and Local Government, London.

DCLG, 2009. Multi-criteria analysis: a manual. Department for Communities and Local Government, London.

DECC, 2009. Climate change act 2008: Impact assessment. Department of Energy and Climate Change, London.

DECC, 2012. Energy consumption in the United Kingdom. Department of Energy and Climate Change, London.

Doukas, H. C., Andreas, B. M., Psarras, J. E., 2007. Multi-criteria decision aid for the formulation of sustainable technological energy priorities using linguistic variables. European Journal of Operational Research. 182(2), 844-855.

Dubois, D., Prade, H. M., 1980. Fuzzy sets and systems: theory and applications. Academic Press, New York. 
ECG-19, 2000. Energy consumption guide 19: Energy use in offices. The Government's Energy Efficiency Best Practice programme, London.

Elden, L., 2007. Matrix methods in data mining and pattern recognition. SIAM, Philadelphia, PA.

Gakovic, B., 2000. Areas and types of glazing and other opening in the nondomestic building stock. Environmental and Planning B: Planning and Design. 27(5), 667-694.

Hawkins, G., 2009. Building services job book, a project framework for engineering services. Building Services Research and Information Association, Bracknell.

HM Government, 2009. Analytical annex : The UK low carbon transition plan. HM Government, London.

Huang, J., Akbari, H., Rainer, L., Ritshard, R., 1991. 481 prototypical commercial buildings for 20 urban market areas. Lawrence Berkeley National Laboratory, Berkeley, California.

Hwang, C., Yoon, K., 1981. Multiple attribute decision making: methods and applications. Springer Verlag, New York.

Jaynes, E. T., 1957. Information theory and statistical mechanics. Physical Review. 106(4), 620630.

Jaynes, E. T., 1982. On the rationale of maximum-entropy methods. Proceedings of the IEEE. 70(9), 939-952.

Jia, J., Fischer, G. W., Dyer, J. S., 1998. Attribute weighting methods and decision quality in the presence of response error: a simulation study. Journal of Behavioral Decision Making. 11(2), 85-105.

Kahraman, C. 2008 'Fuzzy multi-criteria decision making: theory and applications with recent developments', in Kahraman, C. (ed.) Fuzzy multi-criteria decision making: theory and applications with recent developments. New York: Springer.

Kahraman, C., Ertay, T., Büyüközkan, G., 2006. A fuzzy optimization model for QFD planning process using analytic network approach. European Journal of Operational Research. 171(2), 390-411.

Kaya, T., Kahraman, C., 2011. Multicriteria decision making in energy planning using a modified fuzzy TOPSIS methodology. Expert Systems with Applications. 38(6), 65776585.

Klein, S. A., Beckman, W. A., Mitchell, J. W., Duffie, J. A., Duffie, N. A., Freeman, T. L., Mitchell, J. C., Braun, J. E., 2009. TRNSYS 17: A transient system simulation program: Mathematical reference. Solar Energy Laboratory, University of Wisconsin, Wisconsin.

Knight, I., Adnot, J. L., Andre, P., Assimakopoulos, M. N., Butala, V., Hitchin, R., Masoero, M., Spitzbart, C., Wright, D., 2010. HARMONAC-Harmonizing air conditioning inspection and 
audit procedures in tertiary building sector. 2nd edn. Intelligent Energy-Europe (IEE) SAVE project.

Langmaid, J., 2004. Choosing building services. Building Services Research and Information Association, Bracknell.

Lee, S. K., Mogi, G., Kim, J. W., Gim, B. J., 2008. A fuzzy analytic hierarchy process approach for assessing national competitiveness in the hydrogen technology sector. International Journal of Hydrogen Energy. 33(23), 6840-6848.

Mamlook, R., Akash, B. A., Mohsen, M. S., 2001a. A neuro-fuzzy program approach for evaluating electric power generation systems. Energy. 26(6), 619-632.

Mamlook, R., Akash, B. A., Nijmeh, S., 2001b. Fuzzy sets programming to perform evaluation of solar systems in Jordan. Energy Conversion and Management. 42(14), 1717-1726.

Maor, I. H., Panjapornpon, C., Reddy, T. A. (2004) ASHRAE Transactions. Nashville. American Society of Heating, Refrigerating and Air Conditioning Engineers.

Mareschal, B., 1988. Weight stability intervals in multicriteria decision aid. European Journal of Operational Research. 33(1), 54-64.

Milani, A. S., Shanian, A., El-Lahham, C., 2006. Using different ELECTRE methods in strategic planning in the presence of human behavioral resistance. Applied Mathematics and Decision Sciences. 2006, 1-19.

Mundam, G. 2005 'Multiple criteria decision analysis and sustainable development', in Figueira, J., Greco, S. and Ehrgott, M. (eds.) Multiple criteria decision analysis: State of the art surveys. New York: Springer, pp. 953-986.

Murphy, J. M., Sexton, D. M. H., Jenkins, G. J., Boorman, P. M., Booth, B. B. B., Brown, C. C., Clark, R. T., Collins, M., Harris, G. R., Kendon, E. J., Betts, R. A., Brown, S. J., Howard, T. P., Humphrey, K. A., McCarthy, M. P., McDonald, R. E., Stephens, A., Wallace, C., Warren, R., Wilby, R., Wood, R. A., 2009. UK Climate Projections Science Report: Climate change projections. Met Office Hadley Centre, Exeter, UK.

Natee, S., Low, S. P., Teo, L. E. A. 2016 'Decision Making and Quality Function Deployment (QFD)', in Quality Function Deployment for Buildable and Sustainable Construction. Singapore: Springer Singapore, pp. 17-55.

Norris, G. A., Marshall, H. E., 1995. Multiattribute decision analysis method for evaluating buildings and building systems. Building and Fire Research Laboratory, National Institute of Standards and Technology, Gaithersburg.

Phillips, R., 2008. Plan of work: Multi-disciplinary services. Royal Institute of British Architects, London. 
Pout, C., Steadman, J. P., Mortimert, N. D., 1998. None-domestic building energy fact file. Building Research Establishment, Watford.

Ribeiro, R. A., 1996. Fuzzy multiple attribute decision making: a review and new preference elicitation techniques. Fuzzy Sets and Systems. 88(2), 155-81.

Rickaby, P. A., Gorgolewski, M. K., 2000. A classification system for services in nondomestic buildings. Environmental and Planning B: Planning and Design. 27(5), 695-708.

Roy, B., 1996. Multicriteria methodology for decision aiding. Kluwer Academic Publishers, Dordrecht.

Saaty, T. L., 1990. How to make a decision: the analytic hierarchy process. European Journal of Operational Research. 48(1), 9-26.

Satty, T. L., Sodenkamp, M. 2010 'The analytic hierarchy and analytic network measurement processes: The measurement of intangibles', in Zopounidis, C. and Pardalos, P. M. (eds.) Handbook of multicriteria analysis. London: Springer.

Shahrestani, M. 2013 Multiple attribute decision making for HVAC\&R systems selection. PhD thesis. University of Reading.

Shahrestani, M., Cook, G., Yao, R. and Clements-Croome, D. (2017). Decision making on HVAC\&R systems selection: A critical review. Intelligent Buildings International, 1-21. DOI: $10.1080 / 17508975.2017 .1333948$.

Shahrestani, M., Yao, R., Cook, G. K., 2013. Characterising the energy performance of centralised HVAC\&amp;R systems in the UK. Energy and Buildings. 62(0), 239-247.

Shahrestani, M., Yao, R., Cook, G. K., 2014. A review of existing building benchmarks and the development of a set of reference office buildings for England and Wales. Intelligent Buildings International. 6(1), 41-64.

Taylan, O., Kaya, D., Demirbas, A., 2016. An integrated multi attribute decision model for energy efficiency processes in petrochemical industry applying fuzzy set theory. Energy Conversion and Management. 117, 501-512.

Torcellini, P., Deru, M., Griffith, B., Benne, K., Halverson, M., Winiarski, D., Crawley, D. B., 2008. DOE Commercial building benchmark models. National Renewable Energy Laboratory, California.

Trefethen, L. N., Bau, D., 1997. Numerical linear algebra. Society for Industrial Mathematics, Philadelphia.

Turban, E., 1988. Decision support and expert systems: Management support systems. Collier Macmillan, New York.

Tzeng, G. H., Huang, J. J., 2011. Multiple attribute decision making: Methods and applications. CRC Press, Taylor \& Francis Group, Florida. 
Wang, J. J., Jing, Y. Y., Zhang, C. F., 2009a. Fuzzy multi-criteria evaluation model of HVAC schemes in optimal combination weighting method. Building Services Engineering Research and Technology. 30(4), 287-304.

Wang, J. J., Jing, Y. Y., Zhang, C. F., 2009b. Weighting methodologies in multi-criteria evaluations of combined heat and power systems. International Journal of Energy Research. 33(12), 1023-1039.

Wang, J. J., Jing, Y. Y., Zhang, C. F., Shi, G. H., zhang, X. T., 2008a. A fuzzy multi-criteria decisionmaking model for trigeneration system. Energy Policy. 36(10), 3823-3832.

Wang, J. J., Jing, Y. Y., Zhang, C. F., Zhang, X. T., Shi, G. H., 2008b. Integrated evaluation of distributed triple-generation systems using improved grey incidence approach. Energy. 33(9), 1427-1437.

Wang, J. J., Jing, Y. Y., Zhang, C. F., Zhao, J. H., 2009c. Review on multi-criteria decision analysis aid in sustainable energy decision-making. Renewable and Sustainable Energy Reviews. $13,2263-2278$.

Wang, J. J., Zhang, C. F., Jing, Y. Y., zheng, G. Z., 2008c. Using the fuzzy multi-criteria model to select the optimal cool storage system for air conditioning. Energy and Buildings. 40(11), 2059-2066.

$\mathrm{Xu}$, L., Yang, J., 2001. Introduction to multi-criteria decision making and the evidential reasoning approach. Manchester School of Management.

Xu, Z., Zhao, N., 2016. Information fusion for intuitionistic fuzzy decision making: An overview. Information Fusion. 28, 10-23.

Yoon, K. P., Hwang, C. L., 1995. Multiple attribute decision making: an introduction. Sage Publications, California

Zadeh, L. A., 1965. Fuzzy sets. Information and Control. 8(3), 338-353.

Zanakis, S. H., Solomon, A., Wishart, N., Dublish, S., 1998. Multi-attribute decision making: A simulation comparison of select methods. European Journal of Operational Research. 107(3), 507-529.

Zimmermann, H. J., 2001. Fuzzy set theory and its applications. Kluwer Academic Publisher, Boston, Dordrecht and London. 


\section{Appendix: The confirmatory analysis of the determined ranks of the alternatives}

In a MADM problem, using different weighting methods such as subjective, objective and combined methods may result in different ranking (Zanakis et al., 1998; Wang et al., 2009b). Therefore, the confirmatory analysis is applied to assess the consistency, reliability and therefore, relative rationality of the outcomes of the adopted weighting method compared to other weighting methods.

Consider a decision making problem including ' $\mathrm{n}$ ' alternatives that is analysed $u$ sing ' $\mathrm{m}$ ' weighting methods. The final rank of the alternatives can be determined in 'sequence value matrix' $(B)$ as shown in the following equation:

\section{Alterntives}

$$
\begin{aligned}
& \begin{array}{llll}
A L_{1} & A L_{2} & \ldots & A L_{n} \\
\hline
\end{array} \\
& B=\left[\begin{array}{cccc}
b_{1,1} & b_{1,2} & \ldots & b_{1, n} \\
b_{2,1} & b_{2,2} & \ldots & b_{2, n} \\
\cdot & \cdot & \ldots & \cdot \\
b_{m, 1} & b_{m, 2} & \ldots & b_{m, n}
\end{array}\right]_{m \times n} \quad \begin{array}{l}
\text { Method } \\
m_{1} \\
m_{2} \\
\cdot
\end{array}
\end{aligned}
$$

For such a case, an aggregation Singular Value Decomposition (SVD) method can be used to analyse the sequence value matrix $(B)$ and determine the relative rationality of the ranking applied to the alternatives by the adopted decision making methods. (Trefethen and Bau, 1997; Wang et al., 2009b).

Using the SVD method, the rectangular matrix (B) can be decomposed into three matrices including an orthogonal matrix $(\mathrm{U})$, a diagonal matrix $(\mathrm{S})$ and the transpose of an orthogonal matrix (V). This decomposition is commonly shown by the following equation (Elden, 2007):

$B_{m, n}=U_{m \times m} S_{m \times n} V_{n \times n}^{T}$

The characteristics of the sequence value matrix (B) can be represented by non-zero singular values $(\sigma)$ of the diagonal matrix (S). The number of these non-zero singular values is equal or lower than $\mathrm{p}=\operatorname{Min}(\mathrm{m}, \mathrm{n})$. Therefore, there are ' $\mathrm{p}$ ' singular values represented by $\left(\sigma_{i}, \ldots, \sigma_{p}\right.$ ). The larger singular value describes more characteristics of the matrix ' $\mathrm{B}$ ' than the smaller singular values (Wang et al., 2009b). 
The first step of confirmatory analysis is to develop the approximate matrix $(\hat{S})$ of the original matrix ' $S$ '. The larger anterior ' $k$ ' singular values of the original matrix ' $S$ ' are kept and the rest are set to zero. Consequently, ' $k$ ' approximate matrices $\hat{S}$ would be reproduced using this process. For the first approximate matrix $\left(\widehat{S}_{1}\right)$, only the biggest singular value of the original matrix ' $S$ ' is kept and the rest are changed to zero. In the second approximate matrix $\widehat{S}_{2}$, the first two biggest singular values are kept and the rest are set to zero. Finally, for the last approximate matrix $\widehat{S}_{k}$, all the ' $\mathrm{k}$ ' singular value of the original matrix ' $\mathrm{S}$ ' are kept. Then, ' $\mathrm{k}$ ' approximate sequence value matrices $\left(\widehat{B}_{1}, \ldots, \hat{B}_{k}\right)$ are back calculated using these approximate matrices $\widehat{S}_{k}, k=1, \ldots, p$ according to the following equation:

$\hat{B}_{k}=U \hat{S}_{k} V^{T}$, for $\mathrm{k}=1, \ldots, \mathrm{p}$

Where, $\widehat{B}_{k}$ is the approximate of the sequence value matrix $(B)$, which is back calculated using the approximate matrices $\widehat{S}_{k}, k=1, \ldots, p$. In the next step, from among the different ' $k$ ' values, one should selected in a way that its associated $\widehat{B}_{k}$ has the least deviation from $B$ in terms of consistency and reliability. The consistent degree $\eta_{k} \in[0,1]$ is defined as the level of closeness between $\widehat{B}_{k}$ and $\widehat{B}_{1}$ according to the following equation (Wang et al., 2009b):

$\eta_{k}=\frac{\|B\|_{F}-\left\|\hat{B}_{K}\right\|_{F}}{\|B\|_{F}-\left\|\hat{B}_{1}\right\|_{F}}, \quad$ For $\mathrm{k}=1, \ldots, \mathrm{p}$

Where, $\|\cdot\|_{F}$ is the Frobenius norm of matrix ' $x$ ' and $\widehat{B}_{1}$ is the approximate sequence value matrix that generated by back calculation using Equation 34 and considering only the largest singular value kept in the first approximate matrix $\widehat{S}_{1}$.

Also, the reliability degree $\varepsilon_{k} \in[0,1]$ is defined as the level of closeness between $\widehat{B}_{k}$ and $B$ according to the following equation (Wang et al., 2009b):

$\varepsilon_{k}=\sum_{i=1}^{k}\left(\frac{\sigma_{i}}{\sum_{j=1}^{p} \sigma_{j}}\right), \quad$ For $\mathrm{i}=1, \ldots, \mathrm{k}$, and $1 \leq \mathrm{k} \leq \mathrm{p}$ 
In order to meet these two aspects, the consistency and reliability degrees simultaneously, a parameter called 'consistent and reliability degree' $\pi_{k} \in[0,1]$ is defined using the following equations (Wang et al., 2009b):

$\pi_{k}=\alpha_{1} v_{k}+\alpha_{2} \tau_{k}, \quad$ where, $\alpha_{1}, \alpha_{2} \in[0-1], \alpha_{1}+\alpha_{2}=1$

$v_{k}=\beta_{1} \eta_{k}+\beta_{2} \varepsilon_{k}, \quad$ where, $\beta_{1}, \beta_{2} \in[0-1], \beta_{1}+\beta_{2}=1$

$\tau_{k}=\eta_{k} \varepsilon_{k}, \quad$ For $\mathrm{k}=1, \ldots, \mathrm{p}$

Where, $v_{k}$ and $\tau_{k}$ respectively represent the linear and nonlinear combination between the consistent degree $\left(\eta_{k}\right)$ and the reliability degree $\left(\varepsilon_{k}\right)$. Based on the relative importance between the consistent degree $\left(\eta_{k}\right)$ and the reliability degree $\left(\varepsilon_{k}\right)$, the coefficients $\beta_{1}$ and $\beta_{2}$ are defined. In addition, to maximise the holistic discretisation of $\left\{\pi_{k} \mid k=1, \ldots, \mathrm{p}\right\}$ which expresses the difference between 'consistent and reliability degree' $\left(\pi_{k}\right)$ for $k=1, \ldots, p$, the optimised values of $\alpha_{1}$ and $\alpha_{2}$ are determined using the following optimisation equation (Wang et al., 2009b):

$\operatorname{Max} \sum_{k=1}^{p}\left[\alpha_{1} v_{k}+\alpha_{2} \tau_{k}-\frac{1}{p} \sum_{k=1}^{p}\left(\alpha_{1} v_{k}+\alpha_{2} \tau_{k}\right)\right]^{2}$, Where, $\alpha_{1}{ }^{2}+\alpha_{2}^{2}=1, \alpha_{1}, \alpha_{2} \geq 0$

The values of $\alpha_{1}$ and $\alpha_{2}$ determined from Equation 40 are then normalised and used in Equation 37 to provide the 'consistent and reliability degree' $\left(\pi_{k}\right)$, for $k=1, \ldots, p$. In the next step, the ' $k$ ' value associated with the maximum $\pi_{k}$ is determined. The associated approximate sequence value matrix $\left(\widehat{B}_{k}\right)$ to the chosen ' $\mathrm{k}$ ' value is the most consistent and reliable approximation of the original sequence value matrix $(B)$ that is shown in the following equation: 


$$
\begin{aligned}
& \text { Alterntives } \\
& \begin{array}{llll}
A L_{1} & A L_{2} & \ldots & A L_{n}
\end{array} \\
& \text { Methods } \\
& \widehat{B}_{k}=\left[\begin{array}{cccc}
\hat{b}_{1,1} & \hat{b}_{1,2} & \ldots & \hat{b}_{1, n} \\
\hat{b}_{2,1} & \hat{b}_{2,2} & \ldots & \hat{b}_{2, n} \\
\cdot & \cdot & \ldots & \cdot \\
\hat{b}_{m, 1} & \hat{b}_{m, 2} & \ldots & \widehat{b}_{m, n}
\end{array}\right]_{m \times n} \quad \mid \begin{array}{c}
m_{1} \\
m_{2} \\
\cdot \\
m_{m}
\end{array}
\end{aligned}
$$

Here, $\widehat{b}_{m, n}$ represents the back calculated approximate rank of the alternative ' $n$ ' using method ' $m$ '. In the next step, the arithmetic average of these approximate ranks of alternatives for each method is calculated. Then, these average values are used to rank the alternatives; as this rank is the outcome of using the SVD analysis, it is called the SVD ranking method. In this method, the rank of each alternative is presented by ' $R s v d_{j}{ }^{\prime}$, where $j=1, \ldots, n$.

\begin{tabular}{|c|c|c|c|c|}
\hline Approximate ranks & Alternative 1 & Alternative 2 & $\ldots$ & Alternative $\mathbf{n}$ \\
\hline Method 1 & $\widehat{b}_{1,1}$ & $\widehat{b}_{1,2}$ & $\ldots$ & $\widehat{b}_{1, n}$ \\
\hline Method 2 & $\widehat{b}_{2,1}$ & $\widehat{b}_{2,2}$ & $\ldots$ & $\widehat{b}_{2, n}$ \\
\hline$\vdots$ & $:$ & : & $\ldots$ & : \\
\hline Method $\mathrm{m}$ & $\widehat{b}_{m, 1}$ & $\widehat{b}_{m, 2}$ & $\ldots$ & $\widehat{b}_{m, n}$ \\
\hline $\begin{array}{l}\text { The arithmetic average of the } \\
\text { ranks of alternatives using } \\
\text { ' } m \text { ' methods }\end{array}$ & $\sum_{i=1}^{m} \hat{b}_{i, 1} / m$ & $\sum_{i=1}^{m} \hat{b}_{i, 2} / m$ & $\cdots$ & $\sum_{i=1}^{m} \hat{b}_{i, n} / m$ \\
\hline Method m+1 (SVD) & $\operatorname{Rsvd}_{m+1,1}$ & $\operatorname{Rsvd}_{m+1,2}$ & $\ldots$ & $\operatorname{Rsvd}_{m+1, n}$ \\
\hline \multicolumn{5}{|c|}{ 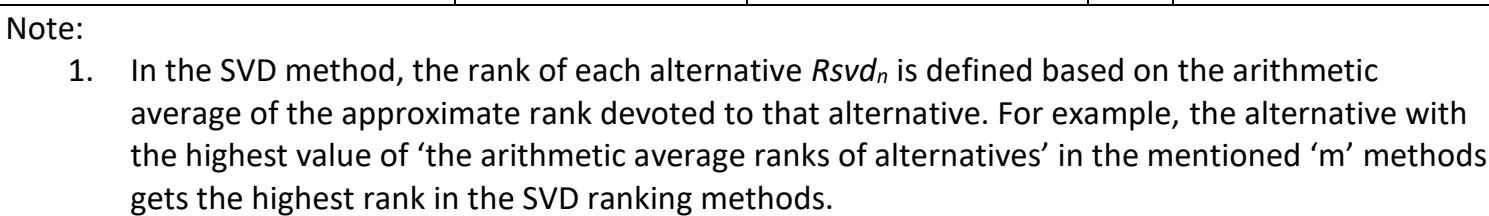 } \\
\hline
\end{tabular}
The process of ranking the alternatives using the SVD method is shown in Table 11.

Table 11 The process of ranking the alternatives using the SVD method from the approximate sequence value matrix $\left(\widehat{B}_{k}\right)$.

Providing a new ranking using the SVD method, now each alternative is ranked by ' $m+1$ ' methods. Therefore, the original sequence value matrix (B) can be amended by the new SVD ranks of the alternatives. This new matrix is called the 'amended sequence value matrix' (BA) and is shown as below: 


$$
\begin{aligned}
& \text { Alterntives }
\end{aligned}
$$

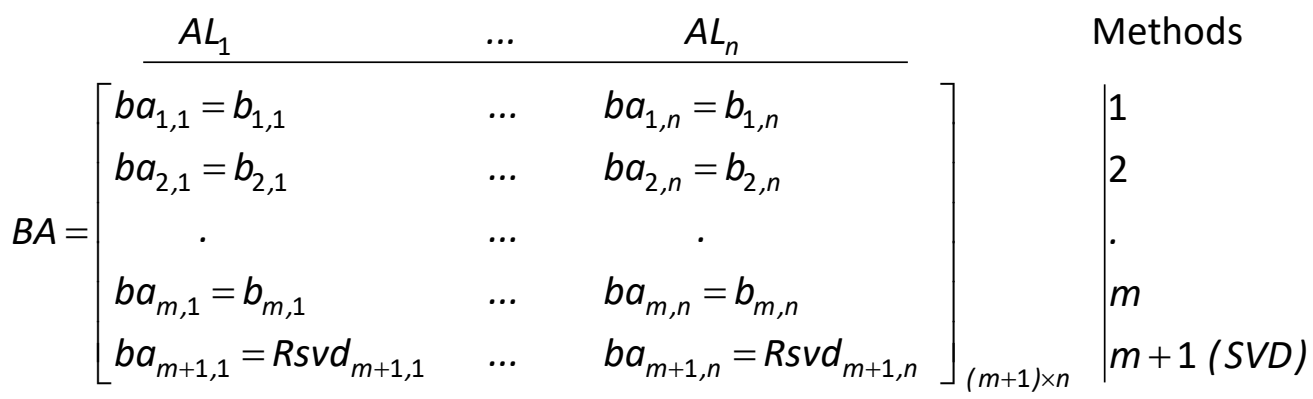

Finally, the Spearman rank correlation coefficient $(\vartheta)$ is used to analyse the relationship between the SVD ranking of the alternatives $\left(R s v d_{i}\right)$, as in Table 11, and the other rankings provided by the aforementioned ' $\mathrm{m}$ ' methods. The Spearman rank correlation coefficient $(\vartheta)$ is calculated using the following equation (Wang et al., 2009b):

$$
\vartheta_{x, y}=1-\frac{6 \sum_{i=1}^{m+1}\left(b a_{i, x}-b a_{i, y}\right)^{2}}{m\left(m^{2}-1\right)}
$$

Where, $\vartheta_{x, y}$ is the Spearman rank correlation coefficient between methods ' $x$ ' and ' $y$ '. This coefficient represents how close the ranking of the alternatives in these two methods ( $x$ and $y)$ is. The larger value of $\vartheta_{x, y}$ shows the higher consistency between the two methods. The Spearman rank correlation coefficients for all pairs of methods are shown in Table 12.

Table 12 The Spearman rank correlation coefficients.

\begin{tabular}{|c|c|c|c|c|c|}
\hline Methods & Method 1 & $\ldots$ & Method $\mathbf{m}$ & Method m+1 (SVD) & Average $(\bar{\vartheta})$ \\
\hline Method 1 & $\vartheta_{1,1}=1$ & $\ldots$ & $\vartheta_{1, m}$ & $\vartheta_{1, m+1}$ & $\sum_{j=1}^{m+1} \vartheta_{1, j} /(m+1)$ \\
\hline$\vdots$ & $\vdots$ & $\vdots$ & $\vdots$ & $\vdots$ & $\vdots$ \\
\hline $\begin{array}{c}\text { Method } \mathbf{m} \\
\begin{array}{c}\text { Method } \mathbf{m + 1} \\
\text { (SVD) }\end{array}\end{array} \vartheta_{m, 1}$ & $\ldots$ & $\vartheta_{m, m}=1$ & $\vartheta_{m, m+1}$ & $\sum_{j=1}^{m+1} \vartheta_{m, j} /(m+1)$ \\
\hline
\end{tabular}

In Table 12, among the different ranking methods, the method that has the closest average Spearman rank correlation coefficient $(\bar{\vartheta})$ to the SVD method can be expressed as a method with the highest consistency in ranking of the alternatives. 
In this study, using this confirmatory analysis, for each scenario, the outcomes of the decision making using subjective, objective and combined weighting methods are compared in order to assess the relative rationality of the outcomes of the adopted combined weighting method.

For instance in the first case scenario specified in Table 9 the alternative systems are ranked based on the three weighting methods: 1-combined weights, 2-subjective weights, and 3objective weights. Following the procedure explained in this section, the Spearman rank correlation coefficient is used to analyse the relationship between the ranking of the alternatives using the SVD method and the other three original methods. The Spearman rank correlation coefficients are provided in Table 13.

Table 13 The Spearman rank correlation coefficients between subjective, objective and combined weighting methods.

\begin{tabular}{|c|c|c|c|c|c|}
\hline \multirow{2}{*}{$\begin{array}{c}\text { Weighting } \\
\text { methods }\end{array}$} & $\begin{array}{c}\text { Method 1: } \\
\text { (combined weights- } \\
\text { adopted approach } \\
\text { in this study) }\end{array}$ & $\begin{array}{c}\text { Method 2: } \\
\text { (Subjective } \\
\text { weights) }\end{array}$ & $\begin{array}{c}\text { Method 3: } \\
\text { (Objective } \\
\text { weights) }\end{array}$ & Method 4 (SVD) & Average ( $\bar{\vartheta})$ \\
\hline Method 1 & 1 & 0.990956 & 0.916454 & 0.994955 & 0.975591 \\
\hline Method 2 & 0.990956 & 1 & 0.869021 & 0.980067 & 0.960011 \\
\hline Method 3 & 0.916454 & 0.869021 & 1 & 0.945123 & 0.932649 \\
\hline Method 4 (SVD) & 0.994955 & 0.980067 & 0.945123 & 1 & 0.980036 \\
\hline
\end{tabular}

The average Spearman rank correlation coefficients $(\bar{\vartheta})$ provided in the last column of Table 13 represent the average consistency between weighting methods. In addition, the closeness of the average Spearman rank correlation coefficient $(\bar{\vartheta})$ of a method to the $\bar{\vartheta}$ of the SVD method represents the rationality of the ranking provided in that method (Wang et al., 2009b). Therefore, this analysis reveals that the weighting approach adopted in this study, Method 1: combination of subjective and objective weights, provides the closest $\bar{\vartheta}$ value to the value at of the SVD method. This confirms the rationality of the rankings of the alternative HVAC\&R systems where compared to singular subjective or objective weighing methods. 